\title{
Steroid Receptors in Breast Cancer: Understanding of Molecular Function as a Basis for Effective Therapy Development
}

\author{
Wojciech Kowalczyk ${ }^{1}$, Grzegorz Waliszczak ${ }^{1}$, Robert Jach ${ }^{2}$ (D) and Joanna Dulińska-Litewka ${ }^{1, *}$ (i) \\ 1 Chair of Medical Biochemistry, Jagiellonian University Medical College, 7 Kopernika St., \\ 31-034 Kraków, Poland; w.kowalczyk@student.uj.edu.pl (W.K.); \\ grzegorz.waliszczak@student.uj.edu.pl (G.W.) \\ 2 Department of Gynecology and Obstetrics, Jagiellonian University Medical College, 23 Kopernika St., \\ 31-501 Kraków, Poland; robert.jach@uj.edu.pl \\ * Correspondence: joanna.dulinska-litewka@uj.edu.pl
}

\section{check for} updates

Citation: Kowalczyk, W.; Waliszczak, G.; Jach, R.;

Dulińska-Litewka, J. Steroid Receptors in Breast Cancer:

Understanding of Molecular Function as a Basis for Effective Therapy

Development. Cancers 2021, 13, 4779. https://doi.org/10.3390/

cancers13194779

Academic Editor:

Luisa Alejandra Helguero

Received: 4 September 2021

Accepted: 20 September 2021

Published: 24 September 2021

Publisher's Note: MDPI stays neutral with regard to jurisdictional claims in published maps and institutional affiliations.

Copyright: (c) 2021 by the authors. Licensee MDPI, Basel, Switzerland. This article is an open access article distributed under the terms and conditions of the Creative Commons Attribution (CC BY) license (https:/ / creativecommons.org/licenses/by/ $4.0 /)$.
Simple Summary: The knowledge we currently possess on the molecular function of steroid receptors in breast cancer is incredibly vast. New research in the field is constantly emerging, including studies focusing on potential therapeutic application of steroid receptors other than estrogen receptor which already serves as a crucial therapy target. Therefore we believe that it is necessary to regularly summarize the data on this topic. The aim of this review is to provide breast cancer researchers with a clear explanation of the complex nature of steroid receptor function, including the most up-to-date information, in order to support the effective development of future hormone therapies.

\begin{abstract}
Breast cancer remains one of the most important health problems worldwide. The family of steroid receptors (SRs), which comprise estrogen (ER), progesterone (PR), androgen (AR), glucocorticoid (GR) and mineralocorticoid (MR) receptors, along with a receptor for a secosteroid-vitamin D, play a crucial role in the pathogenesis of the disease. They function predominantly as nuclear receptors to regulate gene expression, however, their full spectrum of action reaches far beyond this basic mechanism. SRs are involved in a vast variety of interactions with other proteins, including extensive crosstalk with each other. How they affect the biology of a breast cell depends on such factors as post-translational modifications, expression of coregulators, or which SR isoform is predominantly synthesized in a given cellular context. Although ER has been successfully utilized as a breast cancer therapy target for years, research on therapeutic application of other SRs is still ongoing. Designing effective hormone therapies requires thorough understanding of the molecular function of the SRs. Over the past decades, huge amount of data was obtained in multiple studies exploring this field, therefore in this review we attempt to summarize the current knowledge in a comprehensive way.
\end{abstract}

Keywords: breast cancer; steroid receptors; estrogen receptor; progesterone receptor; androgen receptor; glucocorticoid receptor; mineralocorticoid receptor; vitamin D receptor; molecular function

\section{Introduction}

In 2020, breast cancer became the most frequently diagnosed cancer worldwide, regardless of the sex. In women, it accounted for almost a quarter $(24.5 \%)$ of all cancer cases and remained the most common cancer-related death cause [1]. Steroid receptors (SRs) have long been known as key players in breast cancer pathophysiology. Over the past decades, they have been extensively studied but still remain a major subject of breast cancer research.

Steroid receptors are polypeptides which belong to a superfamily of so called nuclear receptors-evolutionarily and structurally related cytoplasmatic proteins able to translocate to the nucleus where they act as transcription factors (TFs) to modulate the expression of certain genes [2]. The family of SRs comprises estrogen (ER), progesterone (PR), androgen (AR), glucocorticoid (GR) and mineralocorticoid (MR) receptors [2], all expressed in healthy 
human mammary gland as well as in various types of breast cancer (Expression Atlas https: / / www.ebi.ac.uk/gxa/home [3]). Additionally, our review also covers vitamin D receptor (VDR), the ligand of which is a secosteroid, 1,25-dihydroxyvitamin D3, synthesized from 7-dehydrocholesterol, making it closely related to classical steroid hormones which are cholesterol derivatives (Figure 1) [4]. VDR action considerably affects the function of breast tissue and plays an important role in breast cancer [5]. Membrane receptors for steroid hormones are not a subject of this review.

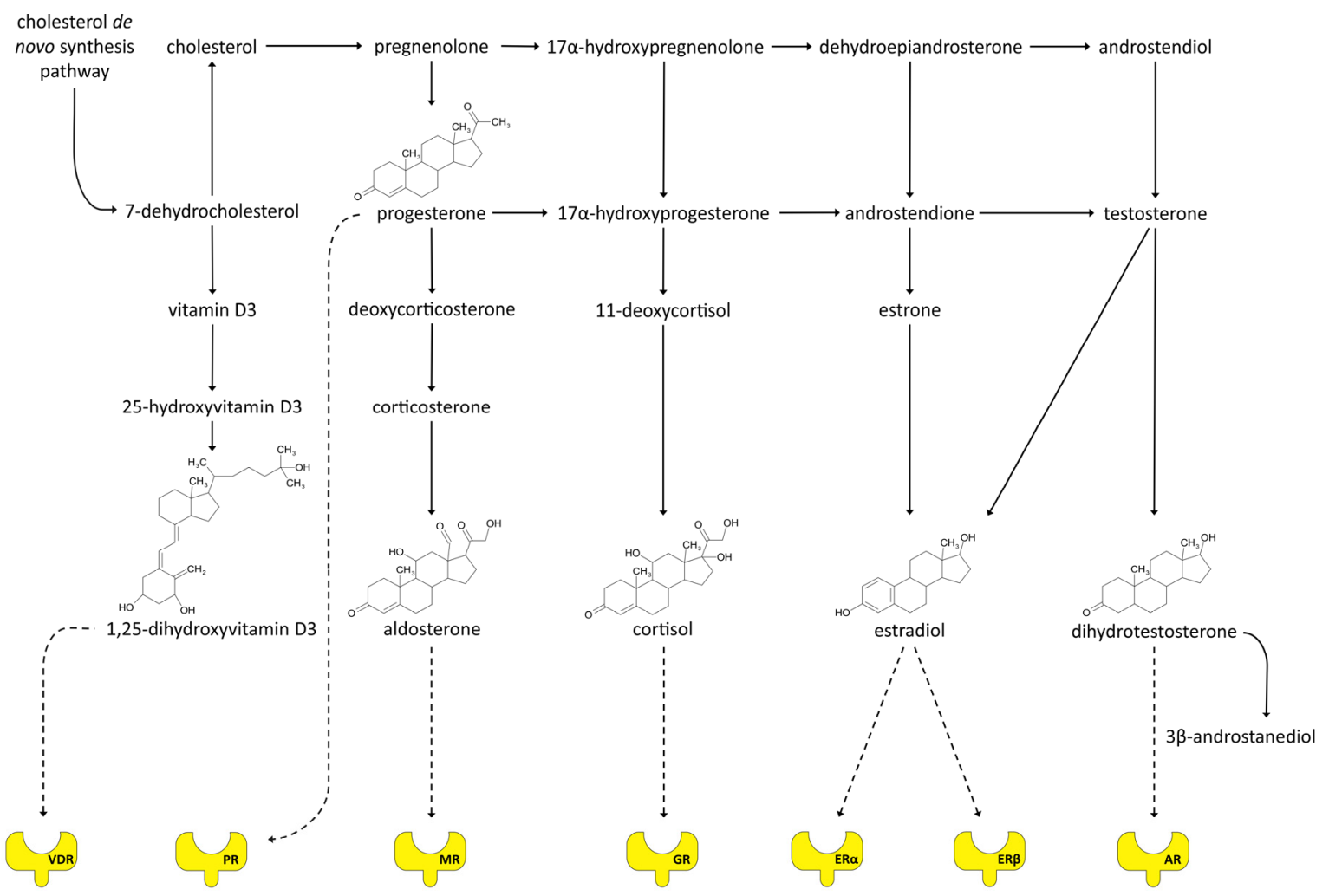

Figure 1. Structure and synthesis of ligands for SRs and VDR. Structures are shown only for steroids of highest affinity to their target receptor [4,6]. Since ER $\alpha$ and ER $\beta$ are encoded by different genes they are shown separately. Solid lines should be read as "is metabolized to" and dotted lines as "binds to". Illustration created using elements from Servier Medical Art https:/ / smart.servier.com/, reproduced under Creative Commons Attribution 3.0 Unported License https:/ / creativecommons.org/licenses/by/3.0/.

Nowadays, breast cancer endocrine therapy is based on targeting ER. The major drugs in use are tamoxifen (selective estrogen receptor modulator-SERM), acting mostly as an ER antagonist, and aromatase inhibitors (AIs) which repress the synthesis of ER ligands by blocking the conversion of androgens to estrogens. However, according to ClinicalTrials. gov (accessed on 30 August 2021), there are also multiple recently completed or ongoing clinical trials investigating drugs targeting SRs other than ER for breast cancer therapy. These studies include e.g., NCT04738292 (onapristone-PR antagonist), NCT02651844 [7], NCT05016349, NCT01138553 (mifepristone-PR antagonist), NCT04947189 (seviteronelandrogen biosynthesis inhibitor), NCT01990209 (orteronel-androgen biosynthesis inhibitor) [8], NCT03383679 (darolutamide-AR antagonist), NCT00637897 (paricalcitolvitamin D analog) [9] or NCT01708798 (eplerenone-MR antagonist; for cardiotoxicity prevention) [10]. Most likely, in the near future further drugs targeting these receptors will be tested. Additionally, there is a possibility that novel therapies aimed at various proteins which interact with SRs will also be designed. Therefore, here we attempt to present the complex aspects of SR molecular function in breast cells, including an in-depth description of PR, AR, GR, MR and VDR and their vast interactomes, understanding of which is crucial 
for developing new approaches in breast cancer endocrine therapy. Our review covers both basic aspects of SR function as well as most recent discoveries in the field.

\section{Molecular Function of Steroid Receptors-Common Features}

Steroid hormones, ligands for SRs, are synthesized in a process called steroidogenesis (Figure 1). Steroidogenesis occurs mainly in adrenal glands and gonads but certain reactions, especially the final conversion of testosterone to dihydrotestosterone (DHT) or to estradiol (aromatization) can take place in many tissues which are often at the same time steroid hormone targets [6]. The cholesterol utilized in steroid synthesis is mainly acquired from serum lipoproteins. Some fraction of the compound is stored in cytoplasm as esters from which it is released by the cholesterol ester hydrolase activated by luteinizing hormone ( $\mathrm{LH})$ or adrenocorticotropic hormone (ACTH). In ovaries, the release of cholesterol and its conversion into pregnenolone is promoted rather by LH than ACTH (as opposed to the adrenal glands) [6].

Steroid receptors share a common ancestry and therefore bear a close structural resemblance to each other, as all consist of four main portions, namely the C-terminal ligand-binding domain (LBD), DNA-binding domain (DBD), hinge region and aminoterminal domain (NTD) [2,11-15] (Figure 2). Each SR contains also two regions called activation function 1 and 2 (AF1 and AF2) which lie within NTD and LBD, respectively, and are crucial for regulation of gene transcription. Two zinc fingers are located in the DBD [2].

AF1

AF2

\begin{tabular}{|l|l|l|l|}
\hline NTD & DBD & H & LBD \\
\hline
\end{tabular}

Figure 2. Schematic illustration of steroid receptor structure. NTD—amino-terminal domain, DBD—DNA-binding domain, $\mathrm{H}$-hinge region, LBD—ligand-binding domain, AF1-activation function 1, AF2-activation function 2. The diagram does not show the exact length proportion of the domains because it differs between distinct SRs.

Canonically, the SR signaling mechanism involves ligand binding, dimerization, nuclear translocation and interaction with DNA. Prior to hormone action most SRs stay in cytosol bound to chaperon protein complexes $[2,16,17]$. Those comprise Heat-shock protein 70 (Hsp70) which is first to recognize and bind the SR, Hsp90- the main chaperone involved and Hop (Hsp70-Hsp90 organizing protein) which facilitates the transition between Hsp70 and Hsp90 systems. Additionally, a variety of proteins serve as Hsp70 or Hsp90 cochaperones. Namely, Hip (Hsp70-interacting protein) and Hsp40 act to support Hsp70, whereas the cochaperones of Hsp90 include p23, Cdc37, PP5 (protein phosphatase 5) as well as immunophilins: FKBP51 (FK506 binding protein 51), FKBP52 and cyclophilin40 [17]. Assembly into these complexes is necessary for proper folding of the nascent receptor, enables the hormone-binding process and represses transcriptional activity of unliganded SR [17].

Upon ligand binding the SR becomes increasingly phosphorylated and the Hsp90 complex dissociates $[2,17,18]$. The process of homo- or heterodimerization then follows, with the latter referring either to the interaction between two different isoforms of the same SR (e.g., PRA-PRB or GR $\alpha$-GR $\beta$ heterodimers) or to one type of receptor binding another as it is for example in case of GR-MR complexes [14,15,19]. Canonically, the dimer initially forms in solution thanks to a contact between the two LBDs and is then further stabilized in the presence of DNA by an interaction of DBDs $[2,12,14,15,20,21]$. However, the remaining domains may also be necessary, as was shown for the NTD and the hinge region of PR [21], or even sufficient (namely, the hinge region of GR [20]) for a dimerization to occur. SR dimer then undergoes a nuclear translocation, enabled by importin proteins bound to the NLS (nuclear localization signal) located at the junction of the DBD and hinge region $[12,15,20,22-24]$.

However, this order of events, where ligand binding precedes dimerization which is then followed by nuclear translocation does not apply in many cases. Hormone binding 
often occurs in the nucleus where some SRs, like GR $\alpha$-D isoform, reside constitutively, whereas others, having been recycled after previous transcriptional action, stay ready to rebind ligand $[2,14,16]$.

Classical SR signaling mechanism, also referred to as direct genomic signaling, involves an interaction between SR dimer and a specific DNA sequence known as HRE (hormone response element) which in this case can be also called SRE (steroid response element) [2,24,25]. Mechanistically, the process involves one of the two zinc fingers of the DBD contacting the major groove of the DNA and the other partaking in the aforementioned DNA-dependent dimerization of the DBDs [2,12]. Core motif of an SRE consists of two six-base-pair-long units separated by a three-base-pair spacer. Each of these hexameric half-sides binds one receptor of an SR dimer [2,12]. Based on which SR class they bind, SREs can be described as EREs (estrogen response elements), PREs (progesterone response elements), AREs (androgen response elements) and GREs (glucocorticoid response elements) which serve as binding sites not only for GR but also for MR [15,26]. Multiple chromatin immunoprecipitation and sequencing (ChIP-seq) analyses carried out in order to determine the exact HRE sequences have shown that that the response elements for single SR type appear in many variants and at the same time SREs for different receptors often share the same sequence [27]. For example the GGTACAnnnTGTTCT motif, which was described as the canonical SRE, can serve as a binding site for GR, MR, PR or AR [2,28,29]. Specificity may possibly be achieved via differences in flanking DNA sequences or spacer nucleotides [2,28]. SREs can be found in promoter regions of SR target genes as well as within enhancer sequences located inside introns or intergenic spaces [19,22,24].

Once bound to the SRE, the SR recruits a plethora of coregulator proteins which could be either coactivators or corepressors of transcriptional activity. Both groups perform histone modifications, remodel the local chromatin and interact with transcription machinery proteins, which in case of the former leads to the assembly and subsequent activity of the RNA polymerase II holocomplex, while in case of the latter results in suppression of gene transcription $[2,22,30]$. Acetylation of the histones at lysine residues by histone acetyltransferases (HATs) is the most commonly described modification leading to gene activation whereas deacetylation, catalyzed by histone deacetylases (HDACs), works in the opposite way [2].

Another common mechanism in which SRs regulate gene expression is called indirect genomic signaling and involves SR tethering other DNA-bound TFs, instead of interacting with SRE $[2,11,19,24]$. Numerous genes, which do not possess SREs in their promoters or enhancers, are regulated by SRs in this manner [11,24]. Both classical and indirect genomic signaling are shown in Figure 3.

Subsequently to hormone dissociation, the SR is detached from the transcriptional complex by molecular chaperones. Hsp90-bound SR then regains the ligand-binding capacity $[16,17]$ (Figure 3). Some SRs can undergo nuclear export which also requires the activity of chaperones [17].

Proteasomal degradation of a SR, following its polyubiquitination, occurs either in the nucleus or in cytoplasm $[16,31,33]$. Hsp70 is suggested to be responsible for making the triage decision between receptor degradation or stabilization [16]. Normally, Hsp70 recruits Hop to promote transfer of a SR to Hsp90 but in case of a damaged or misfolded receptor, an E3 ubiquitin ligase CHIP (Carboxy Terminus Of Hsp70-Interacting Protein) is recruited instead, resulting in polyubiquitination of a SR [16] (Figure 3).

In addition to regulation of gene transcription, which effects occur typically in minutes to hours after hormone exposure, SRs can also act in so-called rapid or non-genomic signaling mechanism, examples of which, along with other non-canonical modes of SR action, are covered in following paragraphs focusing on each type of SR individually $[2,14]$. 




Figure 3. SR synthesis, genomic signaling and degradation. (1) Translation of a SR and binding of Hsp70. (2) Hsp70 to Hsp90 transition. (3) Ligand binding, Hsp90 dissociation and dimerization. (4) Nuclear translocation. (5) Transcriptional action: induction $(5 a, 5 c)$ or inhibition $(5 b, 5 d)$ of target gene expression, performed either in the classical mechanism involving SREbinding $(5 a, 5 b)$ or by tethering other TFs $(5 c, 5 d)$. (6) Ligand dissociation followed by disassembly of the transcriptional complex and SR binding to a molecular chaperone. (7) Rebinding of the ligand. (8) Ubiquitination. (9) Proteasomal degradation. SR—steroid receptor, SH—steroid hormone, Hsp 70—heat shock protein 70, Hsp90-heat shock protein 90, SRE—steroid response element, CoA—coactivators, CoR—corepressors, HAT—histone acetyltransferase, HDAC—histone deacetylase, TF-transcription factor, TFRE-transcription factor response element, Ub-ubiquitin. Although HATs and HDACs are classified as coregulators, here they are shown separately in order to emphasize their role. [2,16,17,31,32]. Illustration created using elements from Servier Medical Art https://smart.servier.com/, reproduced under Creative Commons Attribution 3.0 Unported License https:/ / creativecommons.org/licenses/by/3.0/.

\section{Estrogen Receptor}

Estrogen is an important sex hormone produced predominantly in the ovaries in females and testes in males. Estrogens play an essential role in a number of physiological 
processes, including regulating energy metabolism, stress responses, mineral balance, as well as sexual development [34-36]. Additionally, estrogen is also involved in the function of adipose tissue as well as neuroendocrine, skeletal and cardiovascular systems [37,38].

The biological functions of estrogen are mediated by binding to the ERs: estrogen receptor alpha $(E R \alpha)$ and estrogen receptor beta $(E R \beta)$. The genes coding for ER $\alpha$ and ER $\beta$ are located on chromosome 6, locus 6q25.1 and chromosome 14, locus 14q23.2, respectively. The ER $\beta$ has 530 amino acids and $59 \mathrm{kDa}$ molecular weight, while ER $\alpha$ has 595 amino acids and $66 \mathrm{kDa}$ molecular weight [39]. Five different isoforms of $\mathrm{ER} \alpha(62 \mathrm{kDa}, 53 \mathrm{kDa}$, $46 \mathrm{kDa}, 45 \mathrm{kDa}$, and $36 \mathrm{kDa}$ ) [24], and five ER $\beta$ variants (ER $\beta 1-E R \beta 5)$ are detected in breast cancer [40].

Estrogen signaling is particularly stimulated or inhibited depending upon an equilibrium between ER $\alpha$ and ER $\beta$ activities in the organs. In the 1960s, ER $\alpha$, the first estrogen receptor, was described [41] and now, the function of ER $\alpha$ is well characterized [42] and $\mathrm{ER} \alpha$ is widely used for verifying medication and imaging strategies [43,44]. ER $\alpha$ is predominantly expressed in the uterus and pituitary gland with highest levels in the liver, hypothalamus, bone, mammary gland, cervix, testis, kidney, heart, skeletal muscle, and vagina [45]. In healthy breast glandular epithelium, ER $\alpha$ is expressed by about $30 \%$ of the cells [46]. ER $\alpha$ activation stimulates tumorigenesis in various types of cancer, including breast cancer [47].

The second one, $E R \beta$, has unique functions and shows potential as a novel target for pharmacological intervention [48,49]. The common expression of ER $\beta$ is detected in luminal and myoepithelial cells in the normal breast but also in subcutaneous adipose tissue [50] and testis, prostate, ovary, uterus, and brain tissues [51]. Changes in estrogenic signaling pathways have been discoursed in the physiological and pathological processes [52], neuronal-mediated contractions of the gastrointestinal tract [53], recovery of reproductive system injury [54], anxiolytic effects [55], and diseases such as Parkinson's disease [56] or endometriosis [57]. Furthermore, ER $\beta$ has been shown to take part in the pathological process of various cancers, e.g., colorectal cancer [58], prostate cancer [59] or duct carcinoma [60]. ER $\beta$ expression is also found exclusively in the granulosa cells [61,62]. Both ER $\alpha$ and ER $\beta 1$ require ligand binding for ER target gene transcription [63]. Analysis of $E R \alpha$ and ER $\beta$ tissue distribution suggests that ERs have high specificity on the target tissue [64].

In ligand-dependent ER signaling mechanisms, the binding of estrogen with ER causes a conformational change, which allows various coregulators to stimulate transcription of ER-target genes. As it is for other SRs, the ligand/estrogen-dependent mechanism is further classified into direct genomic or classical, indirect genomic or non-classical, and non-genomic mechanisms of action $[45,65,66]$.

Helix 12 is the functional core of AF2 and is very conserved in ligand-binding domains. The process of binding to a ligand can alter the configuration of helix 12, which leads to an agonistic or antagonistic form of transcriptional regulation [67]. Attachment between $\mathrm{ER}$ and hormone results in a change of conformation in the ligand-binding domain that allows helix 12 to interact with coactivators. The resulting genomic reaction necessitates coactivator binding and is proportional to the magnitude of the reaction. Alternatively, $\mathrm{ER} \alpha$ binds to the DNA with inactive status in the absence of hormones [68,69].

Nuclear factors such as pro-factor FOXA1 (Forkhead Box A1) may affect direct DNA binding by recruiting chromatin at the binding site to remodel it. The chromatin is opened, allowing the ER to enter its regulatory DNA site [70].

In addition to its ability to directly regulate gene expression, estrogen also affects cell signaling and cellular function through rapid membrane-initiation events. Many signaling processes rely on estrogen receptors localized to the plasma membrane. Lipid rafts are critical for ER plasma-membrane localization and play a key role in its membrane-priming effect [71]. Together, the integration of these cellular signaling pathways can mediate genomic activities and rapid nongenomic effects independently and/or complementarily, which activates the effects of estrogen through hormonal response. 
The last proposed mechanism of the operation of the ER is opportunity-based. ER can regulate cellular responses without hormones by being activated by components of growth factor signaling pathways, which is attributed to the phosphorylation process of some serine residues on the ER [72].

In premenopausal women, estrogens are predominantly produced by the ovary [73] The hypothalamus releases gonadotropin-releasing hormone $(\mathrm{GnRH})$, which stimulates the secretion of follicle-stimulating hormone (FSH) and luteinizing hormone (LH). FSH stimulates the biosynthesis of estrogens in growing ovarian follicles, which then act on the hypothalamus to induce the production of LH. An acute rise in LH triggers ovulation and the development of the corpus luteum. After menopause, the ovaries produce negligible levels of estrogens [74]. The importance of gonadal steroidogenesis in normal breast development and in the origin of breast cancer is emphasized by the fact that early menstruation and late menopause are linked to a higher risk of breast cancer [75]. Similarly, late menarche and early menopause (before the age of 40 ) result in a significant reduction in the risk of developing breast cancer [76,77]. It is somewhat paradoxical, therefore, that the majority of breast cancers occur after menopause, when circulating estrogen levels are low.

ER $\beta$ plays an important role in the cell actions and extracellular matrix (ECM) composition of breast cancer cells and may have an effect on important chemokine receptors $[78,79]$ as well involved in the beclin1-dependent autophagic cascade [80].

\section{Progesterone Receptor}

Another receptor, that plays a crucial role in both normal and cancerous mammary gland cells, is the progesterone receptor (PR) which is encoded by the PGR gene found at the 11q22.1 locus (HUGO Gene Nomenclature Committee https: / / www.genenames.org/ [81]). There are two main isoforms of PR: PRA and PRB, both being a product of the PGR gene, but transcribed using alternative promoters, which results in PRA lacking $164 \mathrm{~N}$-terminal amino acids [82].

\subsection{Mechanism of Action}

In the nucleus PR binds to promoter or, more commonly, enhancer regions of numerous genes [19]. ChIP-seq analysis of T47D human breast cancer cells performed by Ballare et al. revealed more than 25000 PR-binding sites in the DNA on the basis of which a PRE sequence was identified [83]. Nevertheless, several millions of human DNA sequences have been then shown to match the proposed PRE, raising the question of what factors may determine whether a certain site would be occupied by the PR or not [83]. One possible explanation, though probably insufficient to account for such a vast disproportion, is the involvement of other TFs including such acting as so called pioneer factors-Proteins responsible for chromatin remodeling in order to provide access to the DNA for other TFs [19,83-85]. Indeed, two members of the STAT family of transcription factors (STAT3, STAT5A) as well as FOXA1 have been postulated to play such role towards the PR [84,85]. However, PR binding does not seem to be dependent on the dislocation of nucleosome core proteins by pioneer factors which is necessary in case of many other TFs. It is suggested that FOXA1 factors occupying the PR-binding sites act on chromatin rather by displacing the H1 histone alone instead of remodeling the whole nucleosome [29,83]. Interestingly, PR itself can act as a pioneer factor for other TFs [84].

Another ChIP-seq study focused on distinguishing between the cistromes of two PR isoforms, showing that the overlap between them is lower than one might expect despite similar binding sequences [82]. Likewise, expression analyses indicate that transcriptomes of PRA and PRB differ significantly, highlighting the need for an isoform-oriented approach in designing future PR-targeting therapies [82,86-88]. However, the difficulty in deeper understanding the PR isoform-specific actions lies in the fact that in vivo most cells coexpress both PR isoforms resulting in coexistence of three different dimer variants, namely the PRA and PRB homodimers as well as the PRA-PRB heterodimer, with most likely distinct 
cistromes and transcriptomes [30,86]. While most studies investigating the PRA- and PRB-dependent gene expression patterns were based on cell lines modified to synthesize only one isoform, providing insight to the genomic action of the homodimer forms alone, a research by Khan et al. compared gene expression in $\operatorname{PRA}(+) \operatorname{PRB}(-), \operatorname{PRA}(-) \operatorname{PRB}(+)$ and $\mathrm{PRA}(+) \mathrm{PRB}(+)$ breast cancer cells showing that indeed a certain subset of genes is regulated exclusively by the PRA-PRB heterodimer [87].

PR is capable of exhibiting both activatory and repressive effect on gene transcription. Several factors have been proved to determine whether the expression of a given gene would be promoted or inhibited by the PR. The localization of the PRE in the enhancer sequence of a target gene for instance, is more associated with transcriptional activation, whereas genes harboring a PRE within their promoter region are more commonly repressed upon PR binding [84]. Furthermore, isoform-specificity of PR action is reflected also here, as studies indicate that in most cellular contexts PRB can be classified as an activator, and PRA as a repressor of transcriptional activity [89]. The reason for this lies in the fact that there are many differences between coregulator interaction profiles of PRA and PRB among which a notable one is that PRA is unable to efficiently recruit coactivator proteins NCOA1 and NCOA2, while showing stronger affinity to the corepressor NCOR2 (SMRT) than PRB (Table 1) $[30,82,90]$. The genomic outcome of PR action depends also on local coregulator expression which has been proved to be different in distinct tissues. It also seems to be affected by the phase of the menstrual cycle or the occurrence of cancerogenesis [30].

Table 1. Coregulators of PR transcriptional action [30,84]. Molecular function of the proteins as stated in the UniProt online database https:/ / www.uniprot.org/ [91]. Depending on the molecular context the BRG1 protein can act as a coactivator (for example serving as a component of the SWI/SNF complex) or as a corepressor [84,91].

\begin{tabular}{|c|c|c|}
\hline $\begin{array}{l}\text { Coregulator } \\
\text { Type }\end{array}$ & Gene (Protein) Name & Molecular Function \\
\hline \multirow{6}{*}{ Coactivator } & $\begin{array}{c}\text { NCOA1 (Nuclear Receptor Coactivator 1) also known as SRC1 } \\
\text { NCOA3 (Nuclear Receptor Coactivator 3) also known as SRC3 } \\
\text { EP300 (Histone acetyltransferase p300) } \\
\text { CREBBP (CREB-binding protein) }\end{array}$ & Acyltransferase, activator \\
\hline & NCOA2 (Nuclear Receptor Coactivator 2) also known as SRC2, TIF2 or GRIP1 & Activator \\
\hline & Components of the SWI/SNF (Switch/Sucrose Non-Fermentable) complex & $\begin{array}{l}\text { Helicase, DNA-binding, hydrolase, chromatin } \\
\text { regulator }\end{array}$ \\
\hline & UBE3A (Ubiquitin-protein ligase E3A) also known as E6AP & Transferase \\
\hline & CARM1 (Histone-arginine methyltransferase CARM1) & Methyltransferase, chromatin regulator \\
\hline & SRA1 (Steroid receptor RNA activator 1) & Receptor, activator \\
\hline \multirow{5}{*}{ Corepressor } & NCOR1 (Nuclear receptor corepressor 1) & DNA-binding, chromatin regulator, repressor \\
\hline & NCOR2 (Nuclear receptor corepressor 1) also known as SMRT & DNA-binding, repressor \\
\hline & $\begin{array}{l}\text { HDAC1 (Histone deacetylase 1) } \\
\text { HDAC2 (Histone deacetylase 2) }\end{array}$ & Hydrolase, chromatin regulator, repressor \\
\hline & $\begin{array}{c}\text { RCOR1 (REST corepressor 1) } \\
\text { CBX3 (Chromobox protein homolog 3) also known as HP1 } \gamma\end{array}$ & Chromatin regulator, repressor \\
\hline & KDM1A (Lysine-specific histone demethylase 1A) also known as LSD1 & $\begin{array}{l}\text { Oxidoreductase, chromatin regulator, } \\
\text { repressor }\end{array}$ \\
\hline \multicolumn{2}{|r|}{ SMARCA4 (Transcription activator BRG1) } & $\begin{array}{l}\text { Helicase, hydrolase, chromatin regulator, } \\
\text { activator, repressor, RNA-binding }\end{array}$ \\
\hline
\end{tabular}

PR indirect genomic signaling involves tethering such TFs as AP-1, SP1 or STAT3, whereas the rapid, extranuclear effects exhibited by the receptor include modulation of certain cellular pathways via direct interactions with cytoplasmic or membrane-associated proteins [11]. Furthermore, under certain conditions, PR can function independently of ligand binding or without dimerization [92,93].

\subsection{Post-Translational Modifications}

Post-translational modifications play a huge role in regulation of PR activity, affecting for example its stability, subcellular localization or promoter selectivity [94,95]. They include phosphorylation, ubiquitination, SUMOylation, acetylation and methylation [19]. 
Several protein kinases are able to catalyze the phosphorylation of the PR, including DNA-PK (DNA-Dependent Protein Kinase), PKA (Protein Kinase A) as well as mitogenic kinases such as CDK2 (Cyclin Dependent Kinase 2), CK2 (Casein Kinase 2) or members of the MAPK (Mitogen-activated Protein Kinase) family (e.g., MAPK1 (p42 MAPK) or MAPK3 (p44 MAPK)) $[19,95,96]$. Phosphorylation partakes in a classical, hormone-induced PR signaling pathway. Ser102, 162, 294, and 345 are involved in this process [19]. However, intensive PR phosphorylation can also lead to a ligand-independent nuclear translocation which often takes place in case of breast cancer due to excessive activity of mitogenic kinases [95]. Phosphorylation of Ser294 by MAPK or CDK2 and Ser400 by CDK2 have been shown to work in such mechanism. In case of the former, the receptor becomes sensitized to lower hormone concentrations. Moreover, the ligand binding process occurs when the PR is already inside the nucleus which significantly accelerates the occurrence of transcriptional effects. Ser400 phosphorylation, on the other hand, enhances the transcriptional activity of unliganded PR [92,94]. Phosphorylation pattern is also an important determinant of PR promoter selectivity. Namely, Ser81 phosphorylation by CK2 results in increased expression of STAT5A and WNT1 and thus plays a role in breast cancer cell biology also possibly affecting the process of inflammation related to breast cancer development and progression [95]. Notably, Ser81 is not present in the truncated PRA isoform [94].

E3 ubiquitin ligases RPF1 (Ribosome Production Factor 1 Homolog), E6-AP as well as BRCA1 can be associated with polyubiquitination of PR. This modification marks it for proteasomal degradation which, paradoxically, leads to increased transcriptional activity, as different stages of transcription may require the receptor either present or removed from its DNA binding site. Indeed, increased ligand stimulated activity of many nuclear receptors is tightly linked with their augmented proteasomal degradation $[19,94]$.

SUMOylation is a post-translational modification involving the attachment of a small protein called SUMO (Small Ubiquitin-Related Modifier) to a target protein. The process resembles very much of ubiquitination with its final ligation step also being catalyzed by enzymes called E3 ligases. However, unlike ubiquitination, SUMOylation does not target proteins for proteasomal degradation but rather stabilizes them or modifies their function. PR can be SUMOylated at its Lys388 residue by an E3 SUMO ligase PIAS1 (Protein Inhibitor of Activated STAT 1) which results mostly in a decreased hormone-dependent stimulation of gene transcription, probably due to promotion of interaction with corepressors. Such mechanism of SUMOylation-induced modification of transcriptional activity have been demonstrated in case of other TFs, like PPAR $\gamma$ (Peroxisome Proliferator Activated Receptor $\gamma)$. PIAS3 has been also proved to affect PR function but it is not clear whether this interaction involves its E3 SUMO ligase activity. Removal of SUMO from the PR, catalyzed by SENPs (SUMO/Sentrin-Specific Proteases), results in upregulated transcription of target genes. SUMOylation-mediated regulation of PR target genes transcription is much more pronounced regarding genes possessing multiple PREs rather than just a single one [94]. Gene signature associated with increased activity of deSUMOylated PR corresponds with endocrine resistance and poor outcome in breast cancer [19].

Acetylation of the PR can occur on a lysine (Lys; K) residue within a conserve KXKK motif located in the hinge region, or on Lys183. In response to hormone stimulation, the KXKK acetylation facilitates the nuclear translocation thus accelerating PR-stimulated transcription of such genes as MYC [19,23]. Lys183 acetylation, which can be catalyzed by p300 coactivator, also enhances PR transcriptional activity, but it does so by increasing its DNA-binding capacity [19].

Last reported post-translational modification of PR is the Lys464 monomethylation which most likely suppresses its transcriptional activity $[19,97]$.

\subsection{Role in Healthy Breast}

In healthy mammary gland, the main effect of progesterone stimulation is cell proliferation and differentiation leading to breast development and growth-The process which takes place mostly during puberty and lactation $[19,92]$. This mitogenic function of the PR is 
exhibited by transcriptional upregulation of cell division associated genes, such as CCND1 (Cyclin D1), MYC or FOS and JUN (components of AP-1 transcription factor) (The Signaling Pathways Project database https://www.signalingpathways.org/index.jsf) [11,98-100]. However, most of the cells aren't affected by progesterone directly, as studies on mouse models indicate that only about $20-40 \%$ of breast luminal epithelial cells express the PR $[11,19]$. Therefore, the progesterone-induced proliferation occurs in two phases. First, during initial $24 \mathrm{~h}$ after progesterone exposure, the PR-positive cells proliferate and synthesize paracrine mitogenic factors, the most important of which is TNFSF11 (Tumor Necrosis Factor Superfamily Member 11), also commonly known as RANKL (Receptor Activator Of Nuclear Factor Kappa B Ligand); which then trigger the proliferation of remaining cells [11]. TNFSF11 is a direct PR target gene. It exhibits its activity by binding to a TNFRSF11A (TNF Receptor Superfamily Member 11a; RANK) membrane receptor which then activates the mitogenic NF-KB (Nuclear Factor Kappa B) signaling pathway [11]. Other paracrine mediators induced by PR in mouse mammary gland include amphiregulin (AREG) and WNT4 (ligands of EGFR (Epidermal Growth Factor Receptor) and FZD (Frizzled) class receptors, respectively), which also act as proliferative factors and trigger the formation of new ducts and secretory alveoli; as well as calcitonin, with its receptors (CALCR) located in breast exclusively on myoepithelial cells, and a chemokine CXCL12 responsible for stimulation of progenitor cells via the CXCR4 receptor [11]. The similar stem cell regulatory function is exhibited by the Notch signaling pathway, with Notch receptors ligands (i.e., JAG1 (Jagged Canonical Notch Ligand 1), DLK1, DLK3 (Delta Like Non-canonical Notch Ligand 1 and 3)) also being upregulated by the PR [101]. Interestingly, it has been suggested that growth hormone $(\mathrm{GH})$ is secreted locally in the breast where it acts as a paracrine mediator and that its synthesis is also stimulated by progestins [101].

\subsection{Role in Breast Cancer}

Progestin-induced PR activity is a well-known factor driving carcinogenesis in the breast. Large epidemiological surveys have shown that usage of progestins as components of either contraceptives or hormone replacement therapies markedly increases breast cancer risk [11,102-107]. On the other hand, once the tumor is established, loss of PR expression in later stages of its development is associated with less differentiated and more aggressive phenotype accounting for worse prognosis [19,92].

Mouse model studies indicated a crucial role of PR action in initiation of tumorigenesis. It is the paracrine signaling, mediated by PR-induced TNFSF11 as well as, possibly, WNT1 and WNT4, that contributes majorly to this process, however, its role gradually decreases as the tumor enters later stages of development. Moreover, there is an observed increase in relative abundance of PR-positive cells from aforementioned $20-40 \%$ in normal breast to approximately $50 \%$ in invasive cancers, which suggests a shift from paracrine to autocrine mode of signaling as a main driver of tumor progression [11,92]. The main mediator of this autocrine signaling is most likely WNT1 [108]. Interestingly, the classical WNT/ $\beta$ catenin pathway doesn't seem to play a major role in this process. It is rather postulated that, upon WNT1 binding, FZD class receptors, as members of the G-protein coupled receptor (GPCR) family, activate the Ras/MAPK cascade by rapidly stimulating, in a still not fully elucidated mechanism, membrane-anchored matrix metalloproteinases (MMPs), e.g., members of the ADAM (A Disintegrin And Metalloproteinase) family, which then cleave away membrane-bound EGFR ligands, such as HBEGF (Heparin Binding EGF Like Growth Factor), TGFA (Transforming Growth Factor Alpha) or AREG, allowing them to interact with their receptors [108-110]. Alternatively, GPCRs can possibly induce the Ras/MAPK pathway without the involvement of MMPs. SRC non-receptor protein tyrosine kinase (PTK) is likely to be involved in both of these mechanisms, as, subsequently to being activated by G $\beta \gamma$ subunit or, supposedly, DVL (Dishevelled) in case of FZD signaling, it may either partake in MMP stimulation or directly phosphorylate cytosolic domain of EGFR to initiate the mitogenic cascade [110-113]. Overall, this PR-induced autocrine signaling accounts for very potent stimulation of cell proliferation, as it further 
augments the already strong pro-proliferative action of PR itself as a TF. Indeed, cyclin D1 has been shown to be upregulated upon progestin treatment both directly by PR-dependent transcription and indirectly via the autocrine mechanism [108].

There are further examples of crosstalk between PR and MAPK signaling. SRC kinase, additionally to the aforementioned mechanism, can be activated by a direct interaction with the PR which serves as an example of PR non-genomic effects. This occurs through the SH3 (SRC Homology 3) domain of SRC binding the proline-rich motif located within the NTD of the PR $[19,92]$. Moreover, the PR-MAPK interplay occurs in both directions, as PR activity is substantially potentiated upon the said phosphorylation of Ser294 by MAPKs. This process drives the progression of breast cancer by reducing its dependence on progestins, thereby contributing to the development of resistance to hormone therapy [92].

PR also interacts extensively with STAT transcription factors which play an important role in breast physiology, as prolactin (PRL) signaling occurs via the PRLR/JAK2/STAT pathway (PRLR - Prolactin Receptor, JAK2-Janus Kinase 2) [19]. Transcription of STAT5A, the main mediator of PRL impact on gene expression, is induced by the PR $[19,98,99]$. As mentioned above, this effect depends on Ser81 phosphorylation which, interestingly, also promotes interaction between PR and STAT5A protein to stimulate the expression of other genes, such as WNT1 and, possibly, TNFSF11 [11,19,114]. Notably, Ser81 phosphorylation by CK2 requires DUSP6 (Dual Specificity Phosphatase 6) acting as a scaffold to bring PR and the kinase close together [95]. Likewise, PR cooperates also with STAT3. They have been shown to associate at promoter regions of such genes as BCL2L1 (Bcl-X) or CDKN1A [19,99].

PR also promotes invasiveness of breast cancer by downregulating GATA3. This TF functions in the mammary gland to promote cell fate determination and maintenance thus, in case of breast cancer, it prevents the loss of tumor differentiation and subsequent metastases. Izzo et al. have shown that both PR isoforms are able to repress the transcription of GATA3 and that this process involves the recruitment of EZH2 corepressor [11,115].

An extensive crosstalk between PR and other SRs is observed in breast cancer cells. PR and ER have been shown to associate in cytoplasm as well as at multiple DNA binding sites, including both progesterone and estrogen response elements. PR-induced transcription of such genes as CCND1 and MYC requires ER colocalizing with PR at the gene promoter [116]. Importantly, studies show that cotreatment with estrogen and progestin redirects ER chromatin binding profile towards sites corresponding to the PR cistrome, and, consistently, results in a gene expression signature similar to that observed after the exposure to progestin alone, but not estrogen alone, thus indicating that PREs are more commonly occupied by ER-PR complexes than EREs $[117,118]$. Consequently, this progestin-induced reprogramming of estrogen signaling suppresses the expression of ER target oncogenes. In line with that, progestin treatment was shown to inhibit the estrogen-driven growth of breast cancer xenografts, acting synergistically with an ER antagonist [117]. However, antiprogestins were found to induce the regression of breast tumors more potently than progestins, which remains consistent with the known mitogenic effect of PR action [82,118]. Furthermore, PR antagonists retain the ability to affect estrogen signaling but act most likely by repressing the ER transcriptional activity rather than reprogramming it $[82,119]$.

In accordance with the aforementioned discrepancies in cistromes and transcriptomes of the two PR isoforms, PRA and PRB have been shown to differentially affect the breast cancer biology, including the estrogen signaling. Namely, both subtypes redirect ER towards new chromatin binding sites, however, much fewer of those is observed in case of PRA which can be, therefore, treated as a repressor of estrogen signaling [82]. In normal tissue the PR isoforms are present in almost equal amounts but in breast cancer cells the PRA:PRB ratio is often disrupted $[11,120,121]$. PRA predominance occurs more frequently which may seem unexpected, as PR mitogenic activity involves mainly transcriptional induction, whereas PRA is more commonly associated with repressive function. However, McFall et al. indicated that PRA could promote the invasiveness of breast cancer in a mechanism involving a certain aspect of ER-PR corsstalk. Namely, PRA could function 
as a transdominant repressor of ER to inhibit ER-mediated regulation of miR-92a-3p and miR-26b-5p transcription, or directly affect the expression of these miRNA molecules, ultimately leading to reduction of the invasiveness-suppressive effect exhibited by estrogen in later phases of tumor development [89]. Another approach to explaining the phenomenon of increased PRA:PRB ratio states that it may be in fact the PRB isoform that is more active which at the same time could be the very reason for its decreased cellular concentration because elevated transcriptional activity is associated with augmented proteasomal degradation $[11,94]$. To this day it has not been fully solved which isoform actually exhibits worse tumorigenic properties. In breast cancer xenografts PRB predominance was shown to account for faster tumor growth and reduced tamoxifen responsiveness [122]. On the contrary, other studies found that patients with PRA-rich breast lesions were more likely to relapse after treatment that included tamoxifen [123,124]. Two more recent studies comparing clinical outcomes in breast cancer patients with gene expression signatures indicative of PRA or PRB predominance yielded inconsistent results, one showing shorter relapse-free and metastasis-free survival [125] and the other better overall survival [82] in patients with PRB-rich tumors. However, what seems clear is that PRA predominance predicts better antiprogestin responsiveness $[125,126]$. Indeed, recently published first results from the MIPRA study, investigating the use of PR antagonist mifepristone for the therapy of breast cancer with high PRA/PRB ratio, seem to be promising [7].

\section{Androgen Receptor}

\subsection{Metabolism of Androgens in Females}

The androgen synthesis in women occurs mainly in the adrenal glands $(25-50 \%$, depending on hormone, with DHEA-S created only therein), in the ovarian stroma (25-50\% respectively) and the ovarian theca (20\% of DHEA). A notable feature of the women's androgen synthesis pathway is the fact that DHEA-S and testosterone-preceding androgens stem in significant amounts from peripheral conversion of estrogens [127].

\subsection{Androgen Receptor Structure and Signaling Pathways}

The androgen receptor (AR) in human is a 110-kDa protein with its gene located on the $\mathrm{X}$ chromosome, in the locus Xq11-Xq12 [12]. Its natural ligands include dihydrotestosterone (DHT), testosterone (with a much lesser potency) and other androgen pathway metabolites that are present in very small concentrations in blood [6]. When unactivated, AR resides in the cytoplasm, bound to heat shock proteins (Hsp90, Hsp70, Hsp56, Hsp27). Contrary to other steroid receptors, its main transcriptional activity is mediated by AF-1 (AF-2 in the others) [128].

Although expressed predominantly by male genital organs, it is also present at variable levels in the cervix and vagina and the acini and ducts of the breast [129]. Approximately $20 \%$ of breast epithelial cells express AR in the healthy tissue [130]. AR is responsible for growth and differentiation in normal breast. Its knock-out or blockage in mice led to 'reduced ductal branching, decreased lobuloalveolar development, fewer milk-producing alveoli (...), altered mammary gland development/morphology'. AR activity is corollary to proliferative stimuli of ER $\alpha$ and serves to counteract and regulate excessive proliferation of breast tissue, that interplay leads to normal ductal development of the breast. In fact, in ER $\alpha$ - cell lines like MDA-MB-453, more than half incidents of AR-DNA interaction occurred at ER-dependent genes; this action seems to be mediated by FOXA1 [131]. Some reported cooperation of AR and ER in growth induction, although it is related more to the binding of the other receptor's ligands than to cooperation [132]. Other studies show that in certain cancer lines (e.g., MCF-7) and in certain ER $\alpha$-negative breast cancers (the molecular apocrine subtype) AR can successfully mimic the cistrome of ER and be pro-proliferative, as it is antiproliferative in luminal breast cancers. AR supports HER2 expression by activating WNT and MYC [133]. In a study, ER- breast tumors exhibited cross-talk between AR and HER2, resulting in their proliferation [134]. 
The first exon of the AR gene, coding the terminal peptide, exhibits a polymorphism of CAG and GGN (polyglutamine and polyglycine stretches, respectively). Excess repetition of CAG may lead to decreased transactivation and transcription of the AR (with greater binding affinity to DHT). It is speculated that shorter CAG polymorphism increases the risk of prostate cancer (although the relation with severity and age of onset is unclear). Shorter CAG stretches are more frequent in African-Americans [135]. One of the probable mechanisms of diseases caused by elongated CAG repeats includes the fact that they destabilize normal protein conformation, leading to formation of antiparallel $\beta$-sheet, aggregates and fibrils similar to those seen in prion and neurodegenerative (e.g., Huntington's disease) diseases [136]. The lesser-studied GGN repeats also influence transactivation of the AR, however, in this case the 23-repeat-sequence is considered the peak of maximal transactivation and the most optimal for AR function, as the lower and higher amounts are associated with diseases (non-neoplasmal) [137]. The meta-analyses on the effect of GGN repeats on prostate carcinogenesis have been inconclusive, with some proving the relation of shorter GGN sequences and prostate cancer [138] and some finding no significance thereof [139], contrary to the clearly proven positive correlation of prostate cancer and CAG repeats [139]. Some studies show that longer CAG repeats are related to earlier diagnosis of breast cancer in women with present BRCA1 mutations [140], although it is contested by others [141] on various bases, including indefinite threshold between 'long' and 'short' CAG repeats, populational differences and the heterogenic cell strains in tumor [142].

BRCA1 induces activity of AR by binding to the activation function domain of NTD. In BRCA-deficient heterozygotes, longer CAG trinucleotide repeats in AR NTD have shown to cause higher risk of BRCA-double null breast cancer-however, it was refuted by other studies. A specific PIK3CA mutation in kinase domain causes higher expression of AR in cancer cells, both in cells with full SR expression and ER, PR deficient [132].

AR forms with constitutive activity are known for prostate cancer; for example, the ARVs (variants) are located mainly in the nucleus (also in breast cancer lines like MDA-MB453) and present constant activity. Lacking AF-2 and a part of LBD, their activity is performed by AF-1 and can be compared to activity of normal ARs [128,133]. A wide range of these C-terminally truncated forms is known (AR-V1 to AR-V18, AR45, ARQ640X, trAR, exonskipping forms, e.g., ARv5es, ARv56es, ARv567es=AR-V12, ARv7es) [128,133,143]. These forms of AR are responsible for antiandrogen resistance in castration-resistant prostate cancer [143]. Normal AR receptors dominate in luminal A cancers and are expressed in lowest amounts in basal cancers [133]. AR-V7 presence is very common (51.5\%) in breast tumor samples, especially in ER $\alpha$ - cancers and is correlated with higher levels of HER-2, other common occurrences of mutated AR include AR45 (25.0\%), AR-V1, AR-V2 or AR-V4 (9.3\%), AR-V3 (16.3\%), AR-V9 (13.7\%) and AR-V13, AR-V15 or AR-V18 (19.5\%). Many breast cancer cell lines, including MDA-MB-453, T47D, ZR-75-1 and MCF-7, express AR-V7 [133].

$\mathrm{AR}$ is known to possess sixteen phosphorylation sites, although some are occupied only in cancer cell lines or after medication (e.g., antiandrogens). Several of them are related to oncotic processes of prostate cancer (Table 2) [128].

AR can be acetylated in the hinge region (K630, K632, K633), in the two latter by p300 and p/CAF, or by Tip60 and deacetylated by HDAC1 and SIRT1. This modification leads to increased transcriptional activity of the receptor and was shown to occur in several prostate cancer cell lines; comparably, deacetylation leads to decreased AR activity [128]. The mentioned lysines (K630, K632) can also be methylated by Set9 and it leads to different expression profiles (expression of PSA, suppression of KLK2, TMPRESS2, NKX3.1, NDRG1). AR can be demethylated by lysine demethylase family (KDM) proteins: KDM4A, KDM4D, KDM4C, KDM4B [128]. K845 and K847 residues can be ubiquitinated: RNF6 causes monoubiquitination and increases transcriptional activity by polyubiquitination, while E3 ligases MDM2 and CHIP cause only polyubiquitination and consequent proteasome degradation. ZIPK coactivator causes polyubiquitinylation and increased activity of AR. E3 ligases such as PIAS1 and PIASx $\alpha$ cause SUMOylation of AR in the cytoplasm, while their E1 and E2 counterparts seem to serve the same function in the nucleus. K386 
and K520 lysines were found to undergo SUMOylation, which in case of AR leads to decreased transcriptional activity, however, several other putative SUMOylation locations are known and their effects vary between cell lines, agent proteins, activation state or treatment. Surprisingly, SUMOylation site mutation caused lower half-life of unbound AR and prolonged half-life in bound AR [128].

Table 2. Phosphorylated residues of the AR and their functional roles. Reprinted from the paper "Posttranslational Modification of the Androgen Receptor in Prostate Cancer" by Van der Steen, Tindall and Huang; published in International Journal of Molecular Sciences (publisher: MDPI), 2013 [128].

\begin{tabular}{|c|c|c|c|}
\hline Residue & Kinase/Phosphatase & Function & References \\
\hline \multirow{2}{*}{ S81 } & CDK1, CDK5, CDK9 & Localization, protein stability & [144] \\
\hline & PP2 & Cell growth, transcription & [145] \\
\hline S94 & PP2 & Transcription & [145] \\
\hline \multirow{2}{*}{ S213 } & PI3K/AKT1 & Localization & [146-148] \\
\hline & PIM-1 & Stability & {$[144,149]$} \\
\hline \multirow{2}{*}{ Y267 } & Ack & Cell growth, transcription & [150-153] \\
\hline & SRC & & \\
\hline T280/S291 & AurA & Cell growth, transcription & [154] \\
\hline S308 & PP2 & Transcription & [145] \\
\hline Y363 & Ack & Cell growth, transcription & [151] \\
\hline \multirow{2}{*}{ S424 } & PP2 & Transcription stability & [145] \\
\hline & PP1 & & \\
\hline \multirow{2}{*}{ S515 } & MAPK & Transcription, degradation & {$[155,156]$} \\
\hline & CDK7 & & \\
\hline Y534 & SRC & Localization, cell cycle, transcription & {$[153,157]$} \\
\hline S578 & & Localization, transcription & [156] \\
\hline \multirow{3}{*}{ S650 } & ERK1/JNK1/p38-alpha & Localization & [158] \\
\hline & & Transcription & [159] \\
\hline & PP1 & Localization & [160] \\
\hline S791 & PI3K/AKT1 & Transcription, apoptosis, localization & [146-148] \\
\hline T850 & PIM-1L & Stability & [161] \\
\hline
\end{tabular}

AR coregulators encompass numerous proteins, with several of particular interest in cancer (Table 3) [162,163].

Table 3. The interactome of AR (citation: if not marked-[162]).

\begin{tabular}{ccc}
\hline Protein Type & Activation-Associated & Suppression-Associated \\
\hline $\begin{array}{c}\text { Components of the chromatin remodeling } \\
\text { complex }\end{array}$ & $\begin{array}{c}\text { ARIP, BRG, hBRM, BAF57, SRG3/BAF155, SRCAP, } \\
\text { hOsa1/BAF250, hOsa2 }\end{array}$ \\
\hline Chromatin structure & HMG-1, HMG-2 \\
\hline Acetyltransferases and deacetylases & $\begin{array}{c}\text { NCOA1 (SRC1) [163], NCOA2 (SRC2), NCOA3 } \\
\text { (SRC3) (Rac3, ACTR, AIB1, p/CIP, TRAM1) [163], } \\
\text { p300, CBP, P/CAF, Tip60 [162,163] }\end{array}$ & HBO1, SIRT1, HDAC7, other HDAC \\
Methyltransferases and demethylases & $\begin{array}{c}\text { CARM1/PRMT5, PRMT1, G9a, NSD1/ARA267 }, \\
\text { LSD1, JHDM2A, JMJD2C [162], KDM4A, KDM4D, } \\
\text { KDM4C, KDM4B [128] }\end{array}$ \\
\hline \multirow{2}{*}{ Ubiquitination/proteasome pathway } & $\begin{array}{c}\text { E6-AP, PIRH2, SNURF/RNF4, ARA54, USP10, } \\
\text { UBCH7 [162], ZIPK [128] }\end{array}$ & Mdm2, Chip, MKRN1 \\
\cline { 2 - 3 } & TSG101 (both groups), ARNIP (no data) \\
\hline
\end{tabular}


Table 3. Cont.

\begin{tabular}{|c|c|c|}
\hline Protein Type & Activation-Associated & Suppression-Associated \\
\hline \multirow{2}{*}{ SUMOylation pathway } & $\begin{array}{l}\text { SUMO-2, SUMO-3, Ubc9, Zimp7, Zimp10, } \\
\text { SENP1 }\end{array}$ & SUMO-1, PIASy, Uba3 \\
\hline & \multicolumn{2}{|c|}{ PIAS1, PIAS3, PIASx $\alpha /$ ARIP3, PIASx $\beta$} \\
\hline \multirow{2}{*}{ Splicing and RNA metabolism } & p54nrb, p102 U5snRNP/ANT-1, p44/MEP50 & hnRNPA1 \\
\hline & \multicolumn{2}{|c|}{ PSF, PSP1, PSP2 (no data) } \\
\hline DNA repair & Ku70, Ku80, DNA-PKc, BRCA1, BRCA2 & Rad9 \\
\hline Chaperones and cochaperones & $\begin{array}{c}\text { Hsp40 (DnaJ, Ydj1p), Hsp90, Hsp70, Cdc37, } \\
\text { FKBP52, FKBP51, Bag-1L }\end{array}$ & DjA1 \\
\hline \multirow{2}{*}{ Cytoskeleton } & actin, supervillin, gelsolin, filamin, $\alpha$-actinin- 2 & filamin-A, transgelin, ARA67/PAT1/APPBP \\
\hline & \multicolumn{2}{|c|}{$\alpha$-actinin- 4} \\
\hline Endocytosis & HIP1, GAK/auxillin2, caveolin-1 & APPL \\
\hline \multirow[t]{2}{*}{$\begin{array}{l}\text { Signal integrators and transducers, scaffolds } \\
\text { and adaptors }\end{array}$} & $\begin{array}{l}\text { ARA55 (Hic5) [163], paxillin, FHL2 (DRAL) } \\
\text { [163], PELP1/MNAR, vinexin- } \alpha \text {, Vav3, Rho } \\
\text { GDI, Ack1, PRK1, RanBPM, ARA24/Ran, } \\
\text { STAT3, } \beta \text {-catenin [162], calreticulin [163] }\end{array}$ & $\begin{array}{c}\text { PAK6, RACK1, Ebp1, Hey1, Hey2, RNase L, } \\
\text { TCF4 }\end{array}$ \\
\hline & \multicolumn{2}{|c|}{ Smad3, GSK-3 $\beta$} \\
\hline Cell cycle regulators & $\begin{array}{l}\text { cyclin E, cdc25B, CDK6, Rb, pp32, RbaK, } \\
\text { AATF/Che-1 [162], RAF (IDE) [163] }\end{array}$ & cyclin D1 \\
\hline Regulators of apoptosis & Par-4 & caspase 8 \\
\hline \multirow{2}{*}{ Viral oncoproteins } & $\mathrm{E} 2, \mathrm{Hbx}$ & \\
\hline & \multicolumn{2}{|c|}{ E6, E7 } \\
\hline \multirow[t]{2}{*}{ Nuclear receptor coregulators } & $\begin{array}{c}\text { Asc-1, Asc-2, Trap/Mediator complex proteins, } \\
\text { CoCoA, NRIP, PNRC, TIF1- } \alpha \text {, MRF1, PDIP1, } \\
\text { Zac1, GT198, ARA70 (RFG, ELE1) [163], } \\
\text { ART-27, ARA160 (TMF) [163], PGC-1 (LEM6), } \\
\text { NCOA2 [163] }\end{array}$ & $\begin{array}{c}\text { Alien, AES, SMRT, NCOR, PATZ, TGIF, TIP110, } \\
\text { TZF, ARR19 }\end{array}$ \\
\hline & \multicolumn{2}{|c|}{ RIP140 (depending on receptor-coregulator ratio-corepressor in high, coactivator in low) [163] } \\
\hline Kinases and phosphatases & MAK, ANPK, Dyrk1A, RSK & ERK8, SCP2, PP2A \\
\hline \multirow[t]{2}{*}{ Transcription factors } & $\begin{array}{c}\text { AML3/CBF } \alpha 1, \text { EGR1, FOXA1, GATA-2, } \\
\text { GATA-3, NF1, PDEF, Sp1, SF1, USF2, SRF } \\
\text { [164], FOXO4 }\end{array}$ & $\begin{array}{c}\text { AP-1, ATF2, c-rel, c/EBP } \alpha, \text { Dax1, ER } \alpha, \text { FKHR, } \\
\text { FoxH1, GR, HoxB13, Pod-1, p53, RelA, SRY, } \\
\text { SHP, TR2, TR4 }\end{array}$ \\
\hline & \multicolumn{2}{|c|}{ Brn-1, c-Jun, Foxa2, Oct-1, RXR, Sox9, Oct-2 (no data) } \\
\hline Other & $\begin{array}{c}\text { DJ-1/PARK7, L-dopa-decarboxylase, } \\
\text { MÁGEA11, SRA }\end{array}$ & LATS2/KPM, PTEN, Tob1, Tob2, DJBP \\
\hline
\end{tabular}

It is estimated that androgen receptors are present in about $80 \%$ of invasive breast cancer cells, with the highest occurrence (95\%) in ER-positive, and the lowest (10-35\%) in triple-negative breast cancers (TNBC) [132,165]. In fact, AR is the most commonly expressed nuclear receptor in breast cancer overall and is overexpressed in $62 \%$ of breast tumor samples [132]. Other studies have reported highest presence of AR in luminal A cancers and lowest in TNBC [131]. ARs are present in 25\% of metastases [131] and in majority of ER-, HER2+ apocrine tumors [132]. In several cases (25\%), AR is the only sex hormone receptor expressed by distant metastases [132]. The absence of androgen receptor correlates positively with mean tumor size (in ER+ tumors), Nottingham grade and the presence of necrosis [165], AR-positivity can be associated with older age of onset, lower stage and grade of cancer, $27 \%$ reduction of overall breast cancer mortality, $46 \%$ reduction of mortality for ER+ breast cancers and $62 \%$ increase of mortality for ER-breast cancers, although only for the 7 years postdiagnosis, as a $48 \%$ increase in mortality in $\mathrm{AR}+$ cancers was noted thereafter. The increasing degree of AR-positivity in ER-cancers is related to poorer prognosis [166]. In ER $\alpha+$ cancers AR is positively related to lower grade, reduced node involvement, longer disease-free survival and these relations are AR level-dependent [131].

AR expression reduces with tumor grade progression in both ductal carcinoma in situ (DCIS) and metastatic carcinoma, yet is expressed at a higher rate than ER at any tumor grade [132]. 
Possible causes for ER and AR crosstalk include AR coexpression with ER, mutual stimulation by respective steroids, inhibitory binding of testosterone by ER $\alpha$ and correlated upregulation of ER $\beta$ [142]. AR upon activation can bind by the DBD to EREs (e.g., vitellogenin, CTSD, PGR) and block ER $\alpha$ transactivation and $17 \beta$-estradiol growth stimulation in MDA-MB-231 cells. It is disputed that this activity is responsible for effectiveness of aromatase inhibitors in breast cancer therapy or androgen therapy with promising results [167]. The androgen pathway may increase endocrine therapy (tamoxifen, anastrozole, fulvestrant) resistance in ER+ cancers by cross-talk with estrogen pathway. AR can stimulate HER2 pathway through phosphorylation of ErbB2, in turn, the AR's expression is prompted by PI3K and mTOR, descendants of HER2 [142,168].

The investigation of AR influence on TNBC yielded mixed results, ranging from increased mortality and metastases through no relation to better prognosis and lesser node involvement [131].

Luminal AR TNBC subtype is known to present $E R \alpha$-similar effects under AR stimulation. Both AR and ER $\alpha$ can form ternary complexes with SRC and MNAR (PELP1), activating various pathways downstream, including MAPK. Direct corepression is also possible, either with AR NTD binding ER $\alpha$ LBD in presence of estradiol or by AR futile interaction with EREs (mediated by AR LBD) [131] One possible mechanism of AR mimicking ER is its influence on p21-In absence of EGFR or other MAPK pathway stimulation, AR activation leads to proliferation (in presence of the forementioned, AR activation is suppressive).

AR expression is positively correlated with HER2 expression; it was shown that AR presence has beneficial effects only in tumors expressing HER, with no influence on outcome of HER2- luminal B cancers [131]. Hyperactivation of HER2 leads to overactivation of AR and in turn causes increased transcription of HER2 gene. PSA expression is stimulated by $A R$ and was shown to indicate more benign forms of breast cancer, lower histological grade and ER positivity, other studies report on the contrary [131,132]. PSA level can be assessed from patient serum or nipple aspirate fluid [132].

Androgen receptor therapy considered in breast cancer includes two main strategies: agonist administration in ER $\alpha+$ cancers and antagonist administration in AR+ TNBC (the 'molecular apocrine disease'), in this case the evaluated drugs include bicalutamide, enzalutamide, abiraterone acetate and orteronel [131]. Archaic therapies featuring sole testosterone administration fell into disuse in about 1970 due to discovery of androgen to estrogen conversion in vivo, lower effectivity than estrogen-related therapy and introduction of SERMs like tamoxifen. Combinatorial therapy targeting MAPK pathway and AR was shown to reduce tumor cell viability and tumor burden. AR expression is a positive outcome factor in tumors treated with medroxyprogesterone acetate [132]. Inhibition of SRF, a transcription factor related to AR in triple negative cancer lines (MDAMB-231 and HS578t) by CCG1423 (N-[2-[(4-Chlorophenyl)amino]-1-methyl-2-oxoethoxy]3,5-bis(trifluoromethyl) benzamide) reduced cell viability and migration [164]. Surprisingly, $\mathrm{AR}+$ cancer cell lines reduce their proliferation in response to either AR agonists or AR antagonists, in the latter case even AR- lines (BT-20, MDA-MB-468, SUM-159PT) are susceptible to enzalutamide and bicalutamide (this can be explained by the drugs' affinity towards GABA-A, CYP27A1 and PR). Treatment of TNBCs with AR agonists, especially accompanied by VDR agonists, leads to G1 phase arrest, increase of apoptosis, reduction of tumorsphere formation efficiency and cancer stem cell features (by deactivation of CD49f, SOX2, and Notch pathways), with epithelial transformation (increase of claudin-4, cytokeratin 18, down-regulation of cytokeratin 5 and vimentin) [134].

\section{Glucocorticoid Receptor}

The glucocorticoid receptor's gene is located in the long arm of chromosome 5 (5q31Y32) and alternatively called NR3C1. When inactive, GR receptor is bound to several chaperone proteins, including hsp90 (by LBD) [169], hsp70, p23 and FK506-family immunophilins [14]. Hsp90 with p23 and Hsp70 maintains structural and functional integrity 
of LBD, promoting nuclear localization of active GR and influences the transcription of GRE-regulated genes. Hsp90 is overexpressed in some cancer cells, leading to abnormal activity of GR, caused by excess affinity of LBD for ligands, aberrant colocalization in the nucleus and increased GR transactivation [169]. GR $\alpha$ is known to heterodimerize with GR $\beta$, AR and MR [170]. GR can bind not only GRE, but also AP-1, AML1, UNKN, NF-kB, HNF3, TAL1, and NF1 response elements [26].

Due to its immense activity, the coactivators and corepressors of GR are numerous, several are described in Table 4.

Table 4. Sample elements of GR interactome and the modifications of the GR [171-173].

\begin{tabular}{|c|c|c|}
\hline & Protein Feature & Protein Name \\
\hline \multirow[t]{3}{*}{ 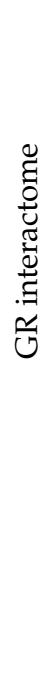 } & Activation-associated & 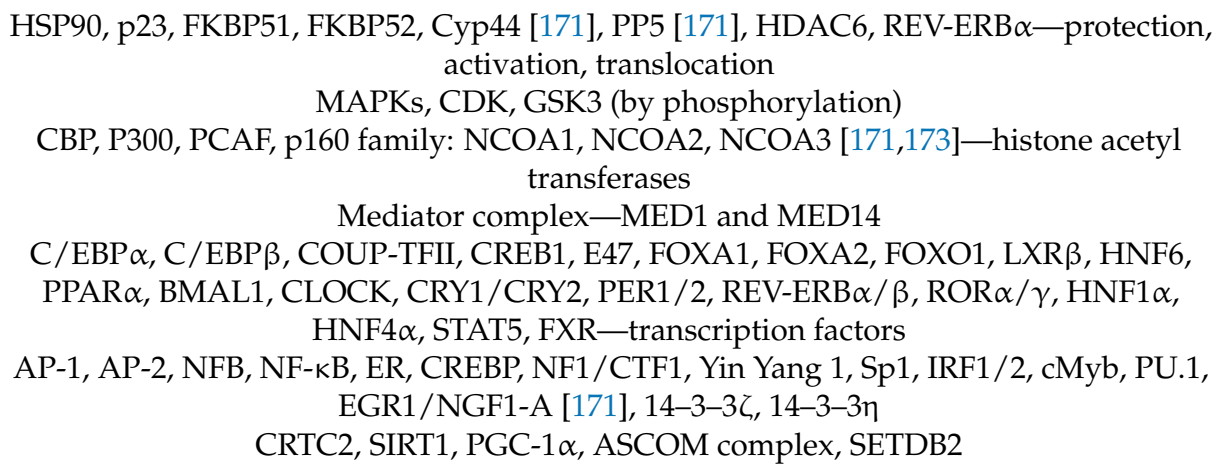 \\
\hline & Suppression-associated & 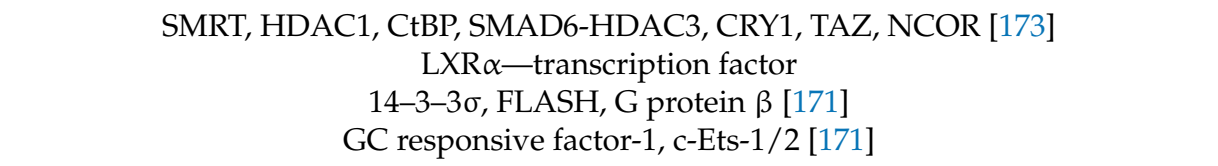 \\
\hline & Deactivated by GR & MAPK, PI3K, TCR complex [171] \\
\hline \multirow{9}{*}{ 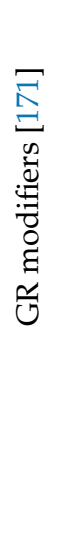 } & Phosphorylation & $\begin{array}{l}\text { CDKs (A-CDK2, A-CDC2, B-CDK2, B-CDC2, E-CDK2, CDK5), p38 MAPKs, AKT, JNKs, } \\
\text { GSK-3 } \beta \text {, ERK, casein kinase II }\end{array}$ \\
\hline & Dephosphorylation & PP1, PP2a, PP5 \\
\hline & Ubiquitination & $\begin{array}{l}\text { E-1, E-2 (UbcH7), E-3 (Hsp70-interacting protein, ET-AP, human homolog of mdm2 } \\
(\text { hmdm2 })+\text { p53) }\end{array}$ \\
\hline & SUMOylation & Ubc9, RSUME \\
\hline & Acetylation & CLOCK, BMAL1 \\
\hline & Deacetylation & HDAC2 \\
\hline & Nitrosylation & neuronal NO synthase, NO donors \\
\hline & Oxidation & $\mathrm{H}_{2} \mathrm{O}_{2}$ \\
\hline & Reduction & dithiothreitol, N-acetyl-L-cysteine, thioredoxin reductase \\
\hline
\end{tabular}

At least seven sites of GR phosphorylation are known [171], but it is unclear what enzymes cause this modification in vivo (in vitro proven for CDKs, MAPKs, JNKs, GSK-3). As with other receptors, phosphorylation leads to increased interaction with cofactors, longer half-life, nuclear translocation, alternation of GRE-dependent transcription and increased glucocorticoid-induced apoptosis. Ubiquitylation of Lys419 causes the removal of GR from nucleus and degradation, but unspecified ubiquitylations of GR also resulted in its longer attachment to DNA and altered transcription. SUMOylation (lysines 277, 293, 703) presents effects that are strongly dependent on a given cell type, can lead to repression of AP-1 and NF- $\mathrm{kB}$ sites, inflammatory proteins and to increased affinity towards NCOR1 and SMRT, but in general seems to increase expression of genes related to cell proliferation, growth and survival. GR can be acetylated at Lys494 and Lys495 by CLOCK and BMAL1. That leads to reduction of its effects on the cell; this modification can be reverted by HDAC2. Nitrosylation of GR may occur at four cysteine residues, however, its consequences are 
unknown, inferring from other receptors, nitric oxide reduces their affinity to DNA and dimerization rate [174].

Several isoforms of GR have been described to this day: GR $\alpha$ (the 'standard' form), GR $\beta$-Which is present in the nucleus (however, some studies revealed its significant presence only in the cytoplasm [175]), has no LBD [169], exhibits constant activity and suppresses the effects of GR $\alpha$. Apart from that, GR $\beta$ possesses other specific DNA targets and is responsible for glucocorticoid resistance. GR $\gamma$ is similar to GR $\alpha$ but exerting less potent effect, GR $\delta$-Expressed in some tissues, GR-P, found in some cancers and other forms, scarcely described (GR-A, GR-DL1, GR-NS1, GR-S1). Multiple variations, caused by alternative translation start (GR-A to GR-D) [14], are tissue-specific and contribute to differentiated effects of glucocorticoids on specific organs due to varied transcription profile and coactivators [171]. Only about 10\% of their targets are shared between them, the $\mathrm{D}$ forms reside exclusively in the nucleus and are the most resistant to glucocorticoid apoptosis induction (and less active in general), in comparison, the $C$ forms are the most prone thereto [14]. Breast cancers do harbor different GR alternative translation start isoforms (GR $\alpha$ A-D) [176].

About 299 genes were shown to be regulated by the 'defective' GR $\beta$ (in HeLa cells), its activation upregulated S100P, ECM1, CGA, FOLR3, ADSSL1, MAFG, ENPEP, SLPI, CACHD1, TRIM29, LOC389203, FGF12 and downregulated FBLN2, UBE2U, SRPK2, CDH2, SELS, VIM, PTPRJ, C8orf4, LIMA1, TCTN1, ABCB1, TGFB2, LUM, TPM1, LOC729113, CA5A, LAMA4, STX1B, UGCG and TNC. For GR $\alpha$, these were SOX2, CANT1, NEK2, ACOX1, TWSG1, ABCG8, LATS2, ESR2, TRNT1, PLXDC1, CEACAM5, PRSS23, DUSP10, PDZD8, DNAL1, TLK1, PELI1, ERP29, FLJ22662, CPA3, MBL2 (upregulated) and FLJ36644, ZNF280B, CLASP2, TDG, IQCK, MPHOSPH9, NLGN1, NRIP1, FLJ10769, MLLT4 (downregulated) [177].

In normal breast, GR activity is necessary for milk production-Including ultrastructural changes in secretory cells, expression of milk proteins and inhibition of gland involution [178].

GR $\beta$, the LBD-free form of GR, deserves special attention. It needs to be addressed that most studies treat GR as whole, disregarding the difference between receptors and thus disallowing conclusions on the exact action and relations of the isoforms.

GR $\beta$ was shown to stimulate the proliferation of LNCaP-ARA70 $\beta$ prostate cancer cells and to have a cross-talk relation with AR. It can be inhibited by mifepristone (as can be GR $\alpha$ ) (2), in turn, ARA70 $\beta$, an AR coactivator, has been found in MCF-7 breast cancer and PC3 prostate cancer lines and was shown to intensively stimulate the expression of NR3C1, which leads to preferential overexpression of GR $\beta$ [179]. GR $\beta$ acts as a dominantnegative inhibitor of $\mathrm{GR} \alpha$, causing glucocorticoid resistance (the other cause of that being the GR $\alpha$ gene loss or GR $\alpha$ phosphorylation) [170]. GR $\beta$ overexpression leads to less COX-2 suppression, excess cytokine (e.g., TNF $\alpha$ and IL-1) production and resulting enforcement of GR $\beta$ expression by NF-k $\beta$ pathway. GR $\beta$ potentiates insulin-dependent cell proliferation by suppressing PTEN and phosphorylating Akt1 in mice. The receptor expression can be induced by insulin or bombesin. In turn, GR $\alpha$ is repressed by Akt1, which phosphorylates its S134 residue [170] GR $\beta$ is preferentially expressed with AR in breast tumors and was revealed to be present in $92.1 \%$ of specimens, typically in triple-negative tumors. It has been shown that its presence is correlated with less vimentin expression in breast tumors in general and in non-triple-negative breast cancers and with lesser proliferation in breast cancers in general [175].

GR expression is positively correlated with ER $\alpha$ expression [180]. In infiltrative lobular carcinomas, these receptors are interdependent; GR suppresses growth, while ER promotes it. Estrogen stimulation leads to GR downregulation $[170,180]$. EREs often overlap with GREs and both hormones can affect the binding site of the other with various effects and the respective receptor remodels chromatin in specific sites, allowing the other to bind with them-Their combined presence (sometimes in a GR/ER complex) leads to increased interaction with AP-1, GATA and FOXO sites and to a more benign phenotype-Induction of VDR (cellular differentiation), KDM4B and others (chromatin remodelers), IGFBP4, 
CCDC88C (negative regulators of Wnt), repression of EMT genes (SNAI2, SOX2, EGR3, KLF9, TRERF1, SUV39H2, ARHGEF26, RHOU, RHOBTB1, ARHGAP36, TBC1D8, RET, DOCK4, CXCL12, LAMA3) [181]. The fact that GR and PR are sensitive to each other's ligands and that GR and PR have about a half of their target genes shared between them is known; progesterone and glucocorticoids can bind to either GR or PR. For example, both induce upregulation of p21CIP1/WAF1 and phospho-p42/p44 (MAPK) protein in ABC28 cells, thereby reducing proliferation. The influence of GR on CTC15 cell morphology (grouping to form islets, cobblestone-like morphology) can be potentiated in presence of PR, whilst the effect is non-significant with PR alone or smaller with GR only. In T47-D cells both PR and GR are known to inhibit proliferation while activated. Activation of an unspecified variety of GR causes transition to $S$ phase and DNA synthesis in CTC15 breast cancer cells [182]. Cross-talk between PR and GR causes growth inhibition and focal adhesion of breast cancer cells [180]. A study has shown no correlation of PR and GR expression in breast tumors [181].

Approximately $62 \%$ of primary invasive breast cancers express GR $\alpha$ [183]. GR mutates readily in many TNBCs [176]. Sporadic breast cancers exhibit BRCA1 downregulation correlated with tumor grade, rate of tumor progression, and risk of metastasis. It was shown that hydrocortisone leads to BRCA1 downregulation in normal breast cells. Unactivated GR binds to a RIBS element, co-acting with such transcription factors as GABP $\beta$ and Fra-2, thus indirectly upregulating transcription of the BRCA1 gene. GR and GABP $\beta$ interact by respectively the DBD and hinge region and $\mathrm{N}$-terminal - central region. Mifepristone also exhibits similar influence on unactivated GR [184]. GR-positivity in ER+ breast cancers contributes to better outcome, and in ER- (triple negative) is related to shorter relapsefree survival [176].

In general, GR level in breast tumors decreases with progression. Worse long-term survival and more recurrence is expected in ER-negative tumors with greater expression of GR [176,183], however, in breast cancer overall GR expression is a sign of better outcome. GR expression was negatively correlated with tumor size, grade, pleomorphism, mitoses, lobular histological type, Ki67, CD71, AGTR1, p53, HER2 expression and HER+/ER+, basal P53 altered and basal P53 normal and triple negative phenotypes. It correlated positively with NPI good prognostic outcome, ER, PR, FOXA1, GATA3, BEX1 and luminal N and $B$ subtypes [183]. Most of the correlations apply only for breast tumors overall and were not proven in ER+ subgroup. In ER- and TN tumors expressing GR, breast cancer specific survival was reduced, but was not an independent predictor of survival in Cox regression model; in other groups there was no association [183]. Another study, to the contrary, reported increased relapse-free survival for ER+ tumors expressing GR, regardless of the presence of PR [181].

GR target molecules induce F-actin and paxillin (focal adhesion proteins) expression and cell spreading in ABC28 cells and were evaluated to suppress their growth, on pair with aldosterone. Dexamethasone and aldosterone stopped the transition to $\mathrm{S}$ phase in mitotic ABC28 cells [182].

Glucocorticoids are antiproliferative towards breast cancer cells and reduce the inflammatory response to the tumor (according to several studies, breast tumor cells overexpress COX-2 which in turn causes prostaglandin production and other pro-proliferative changesThat were proven for immune cell tumors), therefore are used in treatment of primary breast cancer. In comparison, GR activation blocks apoptosis in normal breast epithelium by upregulating MKP-1. It was discovered that with tumor progression GR is translocated to the cytoplasm and its amount in the nucleus is significantly lower than in normal breast cells, surprisingly, this correlates positively with lower level of COX-2 (normally, GR represses COX-2). The exact effect of COX-2 on breast tumorigenesis is unclear, some propose COX-2 elevation as an event in the beginning of breast tumorigenesis, as their studies show its correlation with angiogenesis, lymphoinvasion and cancer progression, but other studies deny that. Cytoplasmic GR expression correlates with lower patient age of onset and with less disease-free time [180]. GR $\alpha$ hinders mitosis by upregulating p27 and p21. 
MCF-7 breast cancer cells present constant upregulation of GR $\beta$ and downregulation of $\mathrm{GR} \alpha$. 5-aza-2'-deoxycytidine (5-dAzaC), sodium butyrate ( $\mathrm{NaBu})$, and trichostatin A (TSA) introduction resulted in reversal of this ratio in several cell lines, including MCF-7 [170].

GR $\alpha$ expression seems to increase chemotherapy resistance and hinder apoptosis in TNBC and normal breast epithelium (via SGK1, MKP1/DUSP1, Forkhead factors and, presumably, reduced cleavage of caspase-3 and PARP); in case of tumors with high expression, this may happen even under physiological levels of cortisol. Introduction of mifepristone, a GR antagonist, with paclitaxel reverses resistance in MDA-MB-231, BT-20 cell lines and in murine MDA-MB-231 xenograft model-GR inhibition alone grants no such effect. A comparable effect was shown in MYC-overexpressing ER-negative MCF10A cell line [176]. In ER+ breast cancers, a therapy with a GR agonist is suggested [181].

\section{Mineralocorticoid Receptor}

MR, along with GR, are an evolutionary result of a gene duplication of a primitive corticoid receptor-with MR retaining the ability to bind aldosterone, 11-deoxycorticosterone and cortisol and GR being selective for cortisol only. Both associate with GREs when activated [26].

MR possesses the longest NTD of all steroid receptors [15,185].

NTD of MR contains five SUMOylation sites (K89, K399, K428, K494 in NTD, K953 in LBD) [15]. MR is SUMOylated by PIAS1 (protein inhibitor of activated STAT (signal transducer and activator of transcription), also known as SUMO-1 E3 ligase), however, the research on its influence yields conflicting results; it imparts no recognisable influence on its activity according to [186] but other studies have shown that SUMOylation leads to decreased transcription of normal GRE-related genes, but not of hemi-sites, degenerated GRE or MMTV promoter sites and that this relation is linearly correlated with the number of SUMOylated sites [15] MR dimers and heterodimers are especially prone to SUMOylation or poly-SUMOylation; SUMOylation may impair dimerisation of MR. SUMOylation can cause receptor translocation to the nucleus, however, it has not been proven to occur for MR. The exact effects of MR phosphorylation in humans are unknown, but those inferred from animal models or other steroid receptors include modulation of transcriptional activity, interaction with other proteins, modulation of its turnover and subcellular trafficking. Phosphorylation of Y73 in NTD in rats leads to significantly higher affinity of MR towards aldosterone and progesterone, similar effect (action enhancement) was noted for NTDrelated phosphorylation by PKA (it is unclear whether PKA phosphorylates MR or its coregulator). Rapid phosphorylation of undefined serines and threonines is caused partly by PKC $\alpha$ and is related to ion transport. K367 in NTD and K715 in hinge are potential ubiquitinylation sites and are purported to increase receptor turnover and decrease its transactivation. Although MR binds Uba3 and Ubc12, it is unknown if its neddylation occurs. K677 of NLS1 is a potential location of MR acetylation by p300 or p/CAF and this modification is supposed to influence homodimerisation-GR heterodimerisation ratio and nuclear transport of the receptor [15].

The NTD of MR possesses neither the binding sequences present in the AR (FxxLF and WxxLF) nor those typical for all steroid receptors (LxxLL) for binding cofactors, thus the N/C-interaction of MR and cofactors is largely AF-2-independent [185]. MR activation is known to be mediated by several coregulators, seldom studied in comparison with other steroid receptors, although the conformation change may occur without cofactors, simply by binding aldosterone (Table 5) [186]. 
Table 5. Interactome of MR (citation: if not marked-[186]).

\begin{tabular}{|c|c|c|}
\hline Protein Feature & Protein Name & Interaction Site \\
\hline \multirow{24}{*}{ Activation-associated } & ELL (elongation factor) & NTD [185], AF-1b [186,187] \\
\hline & SUMO-1-conjugation enzyme (Ubc9) & NTD \\
\hline & NCOA1 (SRC-1) & AF-2, NTD [187] \\
\hline & SRC-1e isoform & AF-1, NTD [187] \\
\hline & NCOA2 & AF-2 [187] \\
\hline & p300/CBP & AF-1 [186], AF-2 [186,187], NLS1/hinge? [15] \\
\hline & PGC-1 $\alpha$ & AF-2 [186-190], LBD [188] \\
\hline & PGC-1 $\beta$ & LBD [188] \\
\hline & $\begin{array}{l}\text { ASC2 (NCOA6, RAP250, AIB3, PRIP, TRBP, NRC), } \\
\text { ASC2-1 }\end{array}$ & LBD [188] \\
\hline & CREBP-BP/RNA helicase complex & NTD \\
\hline & FLASH & AF-1, NTD [187] \\
\hline & CIA & LBD [188] \\
\hline & ARA70-1, ARA70-2 & LBD [188] \\
\hline & FAF-1 & AF-1, NTD [187] \\
\hline & TIF1 [187], TIF1 $\alpha$ & NTD \\
\hline & NSD1 & LBD [188] \\
\hline & RIP140 & NTD \\
\hline & Tesmin & LBD \\
\hline & RHA (RNA helicase A) [185] & AF-1a [187], NTD [191] \\
\hline & GAL4 response element [185] & DBD [186] \\
\hline & PKA [15] & NTD \\
\hline & $\mathrm{p} / \mathrm{CAF}[15]$ & NLS1/hinge (probably p300-related) \\
\hline & EEF1A1, XRCC6, other MR dimers [185], EIF5B [189], & \\
\hline & $\begin{array}{c}\text { AGAP002076-PA—similar [189], PKC } \alpha \text { [15], Uba3, } \\
\text { Ubc12, NEDD [15], HDAC [187]? }\end{array}$ & $?$ \\
\hline \multirow{13}{*}{$\begin{array}{l}\text { Suppression- } \\
\text { associated }\end{array}$} & PIAS1 & NTD/LBD [187] \\
\hline & SMRT & LBD \\
\hline & NCOR & LBD \\
\hline & DAXX & NTD \\
\hline & NF-YC & AF-1 \\
\hline & Gemin 4 & LBD? \\
\hline & PIASx $\beta$ [187] & NTD? \\
\hline & SSRP1 [186,189], ATRX [189], SAFB [189], AHNAK & \\
\hline & [189], BUB3 [189], NPIPL3 [189], CCDC55 [189], RPL4 & \\
\hline & [189], XRCC6 [189], RRBP1 [189], RPL23A [189], & $?$ \\
\hline & SERF2 [189], EEF1A1 [189], ENSA [189], MUC1 [189], & $?$ \\
\hline & $\begin{array}{c}\text { Chloride intracellular channel } 1 \text { variant [189], GPX3 } \\
\text { [189], RRBP1 [189], PCBP2 [189] }\end{array}$ & \\
\hline & MYL2 [189], FRMD4B [189] & $?$ \\
\hline \multirow{3}{*}{ Chaperones } & hsp90 & LBD \\
\hline & hsp70, p23, p48, FKBP-59, CYP40, other & indirectly, via Hsp90 \\
\hline & $\begin{array}{l}\text { immunophilins } \\
\text { actin [187] }\end{array}$ & LBD \\
\hline
\end{tabular}

The chaperone proteins of MR include heat shock protein 90 (hsp90), which interacts directly with the receptor and other, acting indirectly, namely heat shock protein 70 (hsp70), p23, p48, FKBP-59 immunophilins, CYP40 cyclophillin and other immunophilins [15,187]. The exact composition of the complexes varies between different tissue types. The absence of hsp90 leads to deformation of the receptor's structure and inhibition of steroid binding in NRs (it affects predominantly GR and MR) and the fluctuation of its concentration may lead to different transcriptional activity [190]. When not bound by a steroid, the MR forms a hetero-oligomer with a wide range of proteins, especially in the cytoplasm [187].

Target genes of MR include $\alpha / \beta / \gamma$ ENaC subunits, $\alpha 1 / \beta 1$-basolateral $\mathrm{Na}+, \mathrm{K}+-$ ATPase pump subunits, CHIF, K-ras2, SGK1, ELL, GILZ (blocks ERK signaling), Grem2, 
Usp2-45, KS-WNK1 (worth of note because of further PI3K stimulation), NDRG2 (related to N-myc), ET-1, PAI-1, osteopontin, ACE, MDM2, EGF-R (indirectly: fibronectin), collagen I, III, IV (via ERK1/2), tenascin-X (TNX), ADAMTS1, hyaluronic acid synthase-2, RGS2, adrenomedullin, orosomucoid [187] and CNKSR3 [192]. MR blocks apoptosis via its competition for ELL, FAF and FLASH and induces BMP-2-like osteoblastic differentiation and mineralization [187].

Aldosterone exerts some rapid effects on tissues via AT-1 receptor. Active MR can induce SRC, EGFR and MAPK/ERK pathways, in case of the two latter by binding GPER and subsequent activation of EGFR and MEK/ERK. GPER is known to stimulate such pathways as MAPK/ERK, EGFR, PI3K/AKT, in addition to calcium mobilization and cAMP synthesis-resulting in cancer proliferation. By cooperation with HIF-1 GPER promotes VEGF expression and tumor angiogenesis. Various actions mediated by the GPER were assumed to be caused by its function as an aldosterone receptor, recently they are seen rather as the effect of binding with MR. Both MR and GPER are necessary for activation and increased expression of $\mathrm{Na}+/ \mathrm{H}+$ exchanger-1 (NHE-1), a membrane protein involved in proliferation, migration and metastasis of breast cancer that acts in response to hypoxic, acidic tumor microenvironment. Furthermore, aldosterone caused K-RAS upregulation and Raf and Akt activation in renal carcinoma cells and activated another membrane protein, $\mathrm{Na}+$ /HCO3-cotransporter (NBC) [193]. MR acts as an inflammation promoter by upregulating ICAM1, while GR downregulates it [26].

The MR possesses several isoforms: the 'classic' MR and MR+4 variant with four additional aminoacids between the zinc fingers (caused by a cryptic splice site at the exon 3 / intron C splice junction), the $\mathrm{hMR} \alpha$ and $\mathrm{hMR} \beta$ (difference based purely on respective untranslated exons $(1 \alpha, 1 \beta)$, which both yield the same final protein and the only distinction between them can be shown in the mRNA phase as the different stability/efficiency in translation), the $\Delta 5$ or the $\Delta 5,6 \mathrm{hMR}$ isoforms (skipping exon 5 or exons 5 and 6 ) with greatly altered activity (eg. constant activity despite lack of steroids nearby). Two variants called MRA and MRB are caused by different start (Kozak) sequences chosen by ribosomes and are less prone to transactivation than the normal MR (with MRA more potent than MRB) [191]. Several other forms are known in mammals but are not proven in humans. In case of $\mathrm{MR}$ and $\mathrm{MR}+4$, the latter isoform was once thought to be limited in presence to human white blood cells, but now has been shown to appear in various tissues, albeit in comparably smaller amounts than the classic one. There is no difference between their transcriptional activity. Both variants of MR are present in human breast tissue (in ratio of approx. 85:15) $[15,194]$. Several MR mutations are known in cancers $(\geq 5 \%$ of colorectal cancer samples, in cutaneous melanoma, uterine, bladder, and stomach cancers, renal papillary cell carcinoma, glioblastoma multiforme), although none were reported as important for breast cancer development [26].

MR binds mainly aldosterone, although it may bind other mineralocorticoids and even glucocorticoids, based on the presence of $11 \beta$-hydroxysteroid dehydrogenase 2 in target cells (reduces cortisol to cortisone, thus disallowing competition) [15,194]. MR can heterodimerize with other steroid receptors, especially AR and GR [187]. The exertion of PR-like effects by the MR is suspected [175]. MR was shown to be expressed in larger amounts in presence of PR [175]. However, according to some sources, dexamethasone and deoxycorticosterone are weak agonists of MR in the absence of aldosterone, in its presence de facto working as antagonists by suppressing its N/C-interaction and consequent conformation change. Progesterone is stated as either 'weak partial agonist but predominant antagonist', a neutral ligand with no influence on MR in absence of aldosterone or downright antagonist in its presence [185]. Dexamethasone and aldosterone stopped the transition to $S$ phase in ABC28 mitotic cells by blocking DNA replication. The absence of PR in MDA-MB-231-C2 cells led to markedly increased expression of MR. MR activation leads to meagre cell spreading in CTC15 cells [182].

Aldosterone hinders transcription of G6PD, mitochondrial uncoupling proteins UCP1 and UCP3, UPAR and HAS2 [187]. MR suppresses pyruvate kinase via induction of 
miRNA-186-5p, miRNA-95, and miRNA-338-3p, the last in turn suppresses PKLR (miR338-3p-PKLR axis), thereby reducing Wartburg effect by disabling glycolysis, inducing lactate pathway and blocking hepatocellular carcinoma (HCC) proliferation (stopping cell cycle at G1 phase, downregulation of PCNA, apoptosis induction by CASP9 upregulation). Other targets of miR-338-3p include RAB14, SMO, P-Rex2a and SSX2IP (non-small-cell lung carcinoma, hepatocellular carcinoma, neuroblastoma and gastric cancer). MR downregulation was shown in $81.1 \%$ of samples of HCC and correlated with poor prognosis. MR exerted its effect by translocating into the nucleus, spironolactone partially blocked that transition, facilitated colony formation and blocked apoptosis. Deletion of 4q31.1 fragment hosting MR gene seems a peculiar trait of HCC, with $60 \%$ of samples presenting some type of MR loss [192]. In normal condition, PKLR, among other kinases, reduces autophagosome formation downstream or independent of mTORC1 in MCF-7 breast cells and in MCF-10A breast epithelial cells. PKLR silencing led to increased apoptosis despite optimal growth conditions in both lines [195].

The mineralocorticoid receptor (MR) has been shown to be present in both normal and cancer breast cells, with about 79-82.2\% [196] specimens of tumors exhibiting the presence of MR [196], mainly in the cytoplasm [180]. The function of MR in breast tissue has been studied relatively poorly. Aldosterone was shown to elicit some influence on mammary gland development and differentiation and to potentiate prolactin-mediated casein synthesis in the breast of pregnant rabbits [193]. MR level does not seem to fluctuate during breast cancer progression [180]. The presence of MR correlates positively with triple negative breast cancer type, its cytoplasmic presence with node-negativity, more differentiated tumor cells and lesser proliferation and is related to reduced expression of vimentin and increased expression of SIP1 in TNBCs. Its presence reduced the relapse-free survival in non-triple-negative breast cancers (to more extent than tumor size and number of affected nodes), however, it led to better overall outcomes in triple-negative tumors that overexpress it (breast cancer specific survival, overall survival and distant disease-free survival). MR expression may lead to radiotherapy resistance in HER-cancers and to absence of distant metastases, it may induce epithelial-mesenchymal transformation-As of today this phenomenon has not been elucidated. Aldosterone was shown to induce growth suppression in $\mathrm{ABC} 28$ cells [182].

Apart from the treatment of cardiovascular diseases, MR can be exploited in cancer therapy. Prolonged ( $\geq 10$ years) use of ARB/ACEi (angiotensin receptor blockers/angiotensinconverting-enzyme inhibitors) in Western populations significantly reduces breast cancer risk, it is disputed to be caused by suppressing renin-angiotensin II pathway and causing consequent downregulation of TF, VEGF, NF- $\mathrm{KB}$ and CREB. The mentioned drugs block adhesion and invasion of cancer cells by reducing production of integrin $\alpha 3$ and $\beta 1$ subtypes and blocking VEGF-A (the latter proven only in mice) [197]. MR inhibitor (e.g., eplerenone, canrenone, spironolactone) use can be supportive in breast cancer chemotherapy, as it was proven to reduce cardiotoxicity and cardiovascular mortality of patients treated with anthracyclines-By reducing fibrosis, extracellular matrix turnover and myocardial collagen content and leading to better left ventricle parameters, notably lesser decrease of LVEF (left ventricular ejection fraction). A similar effect was shown for ACEi and ARB, although is disputed due to different heart failure criteria and differences in study groups. Candesartan, perindopril and lisinopril have shown a cardioprotective activity in breast cancer patients receiving trastuzumab and anthracyclines [198]. It is possible to insert cell cycle suppressory proteins like p53 (as plasmid) into cancer cells via liposomes harboring spironolactone; a study has shown that such measure leads to apoptosis in MCF-7 and MDA-MB-231 breast cancer cell lines, without toxicity to normal cells. The apoptosis is mediated by upregulation of BAX, cytochrome $C$ and downregulation of Bcl-2 proteins [199]. MR downregulation by histone acetylation or methylation can be reversed by trichostatin A, sodium butyrate and 5-aza-2'-deoxycytidine in HCC lines [192]. 


\section{Vitamin D Receptor}

The information on different isoforms of VDR is scarce. Ten proven isoforms and two putative are known. It is supposed that their expression is tissue-related and that they have different target gene profile, although it has not been elucidated properly as of now [200,201].

VDR is more stable upon binding an appropriate ligand [200]. VDR canonically homodimerizes with other VDR [202] or heterodimerizes with RXR when activated or attaches to a binding site on DNA with pre-bound RXR (the number of these sites increases in osteoblasts after introducing D3), other combinations are also known (VDR-THR, VDRRAR). In the absence of ligands, VDR binds corepressors [203,204]. Regarding VDR-RXR heterodimers, the studied cofactors include CREB-binding protein/p300, steroid receptor coactivator family and SWI/SNF complexes. The RUNX2 and C/EBP $\beta$ also seem to have their actions correlated with VDR [205]. PPARG, BCL6, ESR1, RUNX1, STAT1, MYC and CYP24 seem to be activated by bound VDR and EGR1, SP2, ZNF and STAT1 by free VDR [204]. VDR influences the expression of ITG $\beta 3$, SLC1A1, KDR, BIRC3 and GLUL, exerting an antiproliferative phenotype, promotes CYP24A1, SERPINB1, EFTUD1, CLMN, KLK6 - The three latter are related to better survival in breast cancer [200]. VDR phosphorylation of S208 by casein kinase II seems to lead to increased transcriptional activity, its activity may be decreased by phosphorylation of dimeric partners (RXR $\alpha, S 260$ by Ras/ERK). Other coregulators of VDR include Smad3, TFIIB and c-Jun [202]. VDR expression can be decreased by Ras/ERK pathway (though MEK1, a factor stimulating this pathway, exerted no effect on VDR transcription), either by direct transcription repression, VDR-RXR dimer disruption or p38/MAPK inhibition. p38 and JNK, activated by MKK6 or MEKK1, mediate VDR gene transactivation via c-Jun/AP-1. AP-1, in turn, comprises homodimers of Jun (c-Jun, JunD, JunB) or heterodimers of Jun with Fos (c-Fos, FosB, Fra-1, Fra-2) or others like ATF2, CREB and NFAT. This upregulation leads to reduced growth of MCF-7 cells. MKK6 activity can be substituted with arsenite [202]. Additionally, vitamin D receptor can be corepressed by SIN3/NurD/CoREST, PRC2, TFTC, and SWI/SNF and coactivated by complexes such as INO80, CBP, and SRC3/ncoa3 and WTAP-SFRS [204]. Actually, calcitriol itself can increase the expression of VDR [200,201].

VDR displays some peculiar differences caused by polymorphism of its gene-With the most studied mutations known as Cdx2, Fok1, Bsm1, Apa1, Bg11, Taq1, and Poly (A). According to [206], codominant models such as Bsm1 bb, Apa1 aa, Poly (A) LL, recessive contrast models of Fok1, Apa1, and Poly (A) and allelic contrast model Poly(A) $\mathrm{L}$ are correlated positively with occurrence of breast cancer. There is no proven relation between Cdx2, Bgl1, Taq1 and breast cancer (however, some studies have proven a putative connection with Cdx2) [206].

Vitamin D receptor is expressed by normal lobule, ductal epithelial cells [5], stromal and immune cells [203], adipose cells [200] of human breast and in a higher rate in breast cancer lesions (though there exists some data on the contrary) and in invasive cancers, as compared to in situ cancers or normal tissue [5]. VDR is responsible for breast cell differentiation (ductal differentiation and branching) [201], pubertal development, late pregnancy changes and lactation, calcium transport, casein expression [200] and controlled the menstrual cycle-dependent morphological changes of normal breast tissue in mice [204]. VDR paracrine action between adipose and epithelial breast cells might be important in its normal development and oncogenesis. VDR expression in breast is promoted by lactogens and can be influenced by miR-125b [200]. It may be present intranuclearily, intracytoplasmally and on either cell or nuclear membrane. Cytoplasmal, unactivated VDR promotes proliferation and nuclear, bound form hinders it [5]. Breast tumors in mice are known to accumulate 25-OH-D (incorporating bound DBP by megalin-cubilin complex), however, its significance and presence of this phenomenon is unknown in humans. Nevertheless, breast tissue in humans can synthesize D3 from 25-OH-D by CYP27B1 present therein or acquire it from breast adipose cells, harboring CYP27B1. CYP27B1 expression was reduced in immortalized human breast epithelial cells, inhibiting 
the actions of 1,25-OH-D and similar effect (upregulated cell proliferation, angiogenesis, cell cycle progression, survival markers in tumors, elevated oncogenic pathways like AKT, NF-KB and STAT3) is known for murine PyMT-MMTV model. Presence of such effect in native human breast tumors is unclear. CYP24A1, which reduces 1,25-OH-D to 25-OH-D, was shown to be present in $50 \%$ of breast cancer samples, whereas its expression is low in normal breast tissue (excluding luminal epithelial progenitors). The elevation of CYP24A1 is highly heterogenous and might either have no effects (as a cell possesses high levels of VDR, e.g., MCF-10A, MCF-7, cultivated normal epithelial lines) or promote growth and tumorigenesis (MB-MDA-231). In general, the response of cancer cell lines to 1,25-OH-D is varied and dependent on their specific genome alterations, not on the VDR itself [200].

Although it was shown that breast cancer cells have elevated expression of VDR, they produce exotic receptor variants (V3, V1d") and less full-length variants (V1, V2, V1d, $\mathrm{V} 1 \mathrm{~d}^{\prime}$ ); truncated, downstream aberrant variants (yet unnamed) contribute to much of the VDR-related mRNA production. The V1 and V2 suppression may be caused by promoter hypermethylation [200,201].

VDR is rarely mutated in cancers, albeit can be disabled by aberrant histone deacetylation and methylation of its gene. VDR promoter region (-760--480), $1 \mathrm{a}$ and $1 \mathrm{~d}$ exons of VDR contain several parts (including three $\mathrm{CpG}$ islands) prone to methylation and overlapping with $\mathrm{SP} 1, \mathrm{AP}-2, \mathrm{NF}-\mathrm{kB}$, and transcription start sites. In spite of the fact that methylation occurs in any normal breast samples, breast cancer cell lines (HS578T, 21PT, MCF7, T47D) and breast cancer samples exhibited elevated VDR promoter region methylation and significant hypermethylation of CpGs (40-65\% dinucleotides), as compared to immortalized normal breast line (HBL100) or normal breast samples. In fact, normal breast samples employ meagre levels of methylation (av. 15\%) as compared to breast cancer samples (av. 65\%). Demethylation of these sites by $5^{\prime}$ deoxy-azacytidine led to decreased cell viability in response to calcitriol in all breast cell lines and to increased expression of VDR, $\beta$-actin, p21, C/EBP, CYP27B1 and CYP24A1 [201]. CYP27B1 silencing had similar pro-proliferative effect as VDR silencing as is known to upregulate AKT, NF- $\mathrm{KB}$ and STAT3 pathways, associated with progression [200].

The relation of ER and VDR transcription is unclear: some studies show their coexpression in breast cancer samples and note their related stimulation effects [207], however, other studies either discovered that VDR expression induction does not cause parallel increase of ER [202]. VDR coexpression with AR and ER in cancer-surrounding breast tissue contributed to more favorable outcomes [5]. The research concerning the relation of VDR and ER $\beta$ is, as of now, scarce. A notable apoptotic, pro-differentiative and antimitotic cross-talk between AR and VDR can be utilized in therapy [134]. Knockout of VDR in mice led to enhanced breast gland growth response to estrogen and progesterone in vivo.

VDR was expressed in considerable amounts in $82.9-91.9 \%[5,203]$ of invasive breast cancers. Breast tumor tissues stained for VDR 'almost exclusively' as compared to their surroundings; invasive tumors showing more intense expression of VDR and more nuclearcentred, in situ tumors with cytoplasmic staining [5]. Vitamin D is an antiproliferative agent in breast cancer [203]. The absence of VDR correlated positively with greater tumor size, high Nottingham grade, absence of ER or PR, high expression of Ki67 [5] and lymph node involvement [203]. VDR loss dominates in luminal B-like and triple-negative tumors (with percentage of respectively $25.6 \%$ and $78.4 \%$ of tumors). HER2 negativity also occurs concurrently with low levels of cytoplasmic VDR [203]. Higher VDR levels correlate with higher ER levels in cells [207], with a more benign phenotype and longer relapse-free survival [181]. The presence of VDR precludes less occurrences of mastectomy and lower risk in breast cancer related death in affected patients in general (regarding molecular subtypes of breast cancer, a correlation of less mortality has been proven for luminal B-like tumors and is putative for luminal A-like tumors, while non-significant in triple-negative or basal cancers) [5]. Vitamin D has been found to induce autophagy in luminal-like breast cancer cells (MCF-7, MDA-MB-453, ZR-75-1) and normal stromal breast cells, mainly by upregulation of MAP1LC31B, Beclin1 and a set of other proteins related, however, the 
same effect appeared after VDR knockout [204]. The progression-free survival length is also related to the expression of VDR (with a difference of about 6 years between the groups of patients with low and high expression) [203]. However, studies show conflicting data on the influence of the exact level of the receptor's expression on mentioned parameters [5,203], some even stating no significant influence of VDR expression on the outcome [207]. VDR expression correlates positively with positive outcomes in luminal A breast cancer, especially in cases treated with tamoxifen - probably due to higher ER levels that correlate with more benefit form tamoxifen use [207]. VDR expression halts in highly aggressive tumors [200]. Concluding, VDR expression is related to longer progression-free survival, and overall survival in univariate analyses [5].

The risk of death is equally elevated in patients with not only reduced, but also elevated level of seral vitamin D [5]. The debated influence of D3 on breast cancer proposes some answers to breast cancer statistics: as both VDR and CYP27B1 upregulate during lactation [200], it may be the factor contributing to positive influence of breastfeeding on breast cancer incidence [208]. Similarly, lower levels of D3 after menopause [209], in obese patients [210] and in patients of African or Asian descent living in moderate climate [211] may all result in higher incidence of breast cancer [212].

Vitamin D induced apoptosis via expression of autophagy marker LC3 (LC3A/Bdespite its suppression by inactive VDR), Beclin1, via calcium/calmodulin-dependent protein kinase kinase 2 (CAMKK2) and subsequent AMPK activation [204]. Its apoptotic expression profile appears mostly in normal breast cells and reverses with cancer progression and invasion. For example, in MCF-7 cell line, EGFR, ITPR1, MAP1LC3B, SQSTM1, SAR1A, PRKAR1A and SESN2 were downregulated by vitamin D and PTK6, CLN3, CXCR4, PRKCD, RAB1A, CAPN1, CDKN1B, GNAI3, DRAM1, INSR, ARNT, ZFYVE16, RAB11A - upregulated, while invasive ductal and lobular breast carcinoma cells reacted otherwise. The downregulation of CALCOCO2, KRT13, SAR1A, RAB11A and MAP1LC3B correlated with poorer survival. The same seems to happen to the normal stromal cells, with VDR-related upregulation of HSP90AB1, PRKAR1A, MAPK9, SQSTM1, HIF1A, SAR1A, TGM2, ITPR1 and EGFR, downregulation of DRAM1, CXCR4, ULK2, NRG3, WIPI1, TNFSF10, KLHL24, PI3KC3, ESR1, ATG12, PRKCD, GABARAPL2, CALCOCO2, CAPN1, BNIP3L, RHEB, PTEN, CLN3, PRKAA1, ZFYVE16 (the stroma of invasive cancer repeats the pattern of opposite effect, seen in carcinoma cells) [204]. In MCF-7 the most upregulated genes by calcitriol were respectively CYP24A1, SHE, CRYBB3, TRPV6, ROPN1B, IGHE, ZFP92, RNF222, PRKG2, SH3TC1, IQUB, GOLGA2P2Y, SBK2, NPPC, SLC37A2, SEMA6D, TMPRSS2, MERTK, KLK6, LOC389602 and SNAI2 and the most important target functions are stated as 'pathways involved in muscle cell migration, protein citrullination, negative regulation of cellular processes, negative regulation of locomotion, neuron development and citrulline biosynthetic processes (...) bone morphogenesis, ossification and eyelid development' [207].

BT-20, MDA-MB-468, SUM-159PT, MFM-223, CAL-148, ZR-75-B, and BT-474 cell lines are all susceptible to VDR-induced apoptosis. BT-549, a notable exception, possesses no VDR [134].

Inecalcitol, a vitamin $\mathrm{D}$ analog with less calcaemic potency, was shown to be eighteen times more effective as vitamin $\mathrm{D}$ in apoptosis induction in breast cancer cells, prompting growth halt even in VDR-deficient breast cancer cell lines resistant to vitamin D. VDR activation promotes apoptosis more easily in ER+ lines. This effect is independent of the cells AR or HER2 status. Both compounds reduced cell migration (in MCF-7, BT20, Hs578t(i8), in MDA MB 453-only inecalcitol). Apart from calcitriol-related genes, inecalcitol stimulated CYTH4, LOC553137, MYBPH, GPR78, FREM1, B4GALNT2 and showed preferential upregulation of CLMN, CYP24A1, TMRPSS2, ARHGEF6, FOS, IGFBP3, PISD, G6PD, ITPR1, KLK6, SHE, ACOX3, FSTL4, MERTK and PADI3 [207]. Forskolin and phorbol 12-myristate 13-acetate are also known to unspecifically increase VDR level in cells [202].

As TNBCs do express VDR or AR (about $2 / 3$ of tumors) and some ER+ tumors gain resistance to targeted therapy, they can be treated with VDR agonists (e.g., seocalcitol), es- 
pecially coupled with AR agonists and conventional chemotherapy. This type of treatment leads to G1 phase arrest, increase of apoptosis, reduction of tumorsphere formation efficiency and cancer stem cell features (by deactivation of CD49f, SOX2, and Notch pathways), with epithelial transformation (increase of claudin-4, cytokeratin 18, down-regulation of cytokeratin 5 and vimentin). In this case, vitamin D analogues are preferred to avoid side effects of normal vitamin D in high concentrations [134].

\section{Conclusions}

Most patients in the advanced stage of the neoplastic disease spread and consequently develop numerous symptoms, which is the basis for considering systemic treatment (chemotherapy, hormone therapy, immunotherapy, targeted therapy). The most common indications for hormone therapy include cancers whose growth is dependent on estrogens (breast cancer) and progestins (endometrial cancer) in women and testosterone in men (prostate cancer). Reduction of the effect of hormonal factors on tumor cells can be achieved by inhibiting the synthesis of sex hormones, administering analogues of the luteinizing hormone releasing factor in the pituitary gland (goserelin, leuprorelin), blocking peripheral synthesis (aromatase enzyme inhibitors) or by limiting the direct peripheral influence of sex hormones on receptors located on tumor cells (antiestrogens, antiandrogens). Contrary to chemotherapy, which causes numerous side effects, hormone treatment is much better tolerated and is often continued for the rest of the patients' lives. However, it is important to be aware of the limitations of hormone therapy, which include the subsequent therapeutic response, side effects and drug interactions [213].

The huge therapeutic potential of the SRs together with possible risks associated with endocrine therapies yield a need for constant improvement. Areas to explore include e.g., targeting PR depending on the ratio of isoforms, application of AR antagonists in AR+ TNBC, use of MR antagonists to prevent cardiotoxicity associated with chemotherapy or targeting VDR with vitamin D analogues such as inecalcitol. Given the immense complexity of SRs function in breast cancer, which provides multiple potential therapy targets, it is easy to expect that in the near future many more novel concepts on therapeutic applications of steroid receptors will arise.

Author Contributions: Conceptualization, J.D.-L. and W.K.; formal analysis, W.K., G.W., J.D.-L. and R.J.; methodology, J.D.-L., W.K. and G.W.; investigation, J.D.-L.; data curation, W.K., G.W. and J.D.-L.; writing—original draft preparation, W.K., G.W., J.D.-L. and R.J.; writing—review and editing, W.K., G.W., J.D.-L. and R.J.; drawings, W.K.; visualization, J.D.-L. and W.K.; supervision, J.D.-L.; project administration, J.D.-L.; funding acquisition, J.D.-L. All authors have read and agreed to the published version of the manuscript.

Funding: This research was funded by the Jagiellonian University Medical College.

Acknowledgments: This work was supported by a grant from Ministry of Science \& Higher Education (MNiSW) through Jagiellonian University Medical College (N41/DBS/000431).

Conflicts of Interest: The authors declare no conflict of interest.

\section{References}

1. Sung, H.; Ferlay, J.; Siegel, R.L.; Laversanne, M.; Soerjomataram, I.; Jemal, A.; Bray, F. Global Cancer Statistics 2020: GLOBOCAN Estimates of Incidence and Mortality Worldwide for 36 Cancers in 185 Countries. CA Cancer J. Clin. 2021, 71, 209-249. [CrossRef]

2. Busillo, J.M.; Rhen, T.; Cidlowski, J.A. Steroid Hormone Action. In Yen \& Jaffe's Reproductive Endocrinology; Strauss, J.F., Barbieri, R.L., Seventh, E., Eds.; Elsevier: Philadelphia, PA, USA, 2014; pp. 93-107.e3, ISBN 978-1-4557-2758-2.

3. Papatheodorou, I.; Moreno, P.; Manning, J.; Fuentes, A.M.-P.; George, N.; Fexova, S.; Fonseca, N.A.; Füllgrabe, A.; Green, M.; Huang, N.; et al. Expression Atlas Update: From Tissues to Single Cells. Nucleic Acids Res. 2020, 48, D77-D83. [CrossRef]

4. Strauss, J.F. The Synthesis and Metabolism of Steroid Hormones. In Yen E Jaffe's Reproductive Endocrinology; Strauss, J.F., Barbieri, R.L., Seventh, E., Eds.; Elsevier: Philadelphia, PA, USA, 2014; pp. 66-92.e3, ISBN 978-1-4557-2758-2.

5. Huss, L.; Butt, S.T.; Borgquist, S.; Elebro, K.; Sandsveden, M.; Rosendahl, A.; Manjer, J. Vitamin D Receptor Expression in Invasive Breast Tumors and Breast Cancer Survival. Breast Cancer Res. 2019, 21, 1-13. [CrossRef]

6. Murray, R.K.; Granner, D.K.; Mayes, P.A.; Rodwell, V.W. Harper's Illustrated Biochemistry, 31st ed.; McGraw Hill: New York, NY, USA, 2018; ISBN 978-1-25-983794-4. 
7. Elia, A.; Vanzulli, S.I.; Gass, H.; Lamb, C.A.; Fabris, V.T.; Vazquez, P.M.; Burruchaga, J.; Spengler, E.; Bois, I.C.; Castets, A.; et al. Mipra, a Window of Opportunity Study Evaluating Mifepristone Treatment for Postmenopausal Breast Cancer Patients with Higher Levels of Progesterone Receptor Isoform a than B. In Proceedings of the 2020 San Antonio Breast Cancer Virtual Symposium, San Antonio, TX, USA, 8-11 December 2020; American Association for Cancer Research: Philadelphia, PA, USA, 2021. Abstract nr PS11-35.

8. Yardley, D.; Peacock, N.; Young, R.; Silber, A.; Chung, G.; Webb, C.; Jones, S.; Shastry, M.; Midha, R.; DeBusk, L.; et al. A Phase 2 Study Evaluating Orteronel, an Inhibitor of Androgen Biosynthesis, in Patients with Androgen Receptor (AR)-Expressing Metastatic Breast Cancer: Interim Analysis. In Proceedings of the Thirty-Eighth Annual CTRC-AACR San Antonio Breast Cancer Symposium, San Antonio, TX, USA, 8-12 December 2015; American Association for Cancer Research: Philadelphia, PA, USA, 2016. Abstract nr P5-14-04.

9. Lawrence, J.A.; Akman, S.A.; Melin, S.A.; Case, L.D.; Schwartz, G.G. Oral Paricalcitol (19-nor-1,25- Dihydroxyvitamin D2) in Women Receiving Chemotherapy for Metastatic Breast Cancer: A Feasibility Trial. Cancer Biol. Ther. 2013, 14, 476-480. [CrossRef]

10. Davis, M.K.; Villa, D.; Tsang, T.S.M.; Starovoytov, A.; Gelmon, K.; Virani, S.A. Effect of Eplerenone on Diastolic Function in Women Receiving Anthracycline-Based Chemotherapy for Breast Cancer. JACC Cardio Oncol. 2019, 1, 295-298. [CrossRef]

11. Cenciarini, M.E.; Proietti, C.J. Molecular Mechanisms Underlying Progesterone Receptor Action in Breast Cancer: Insights into Cell Proliferation and Stem Cell Regulation. Steroids 2019, 152, 108503. [CrossRef]

12. Tan, M.E.; Li, J.; Xu, H.E.; Melcher, K.; Yong, E. Androgen Receptor: Structure, Role in Prostate Cancer and Drug Discovery. Acta Pharm. Sin. 2015, 36, 3-23. [CrossRef]

13. Cordera, F.; Jordan, V.C. Steroid Receptors and Their Role in the Biology and Control of Breast Cancer Growth. Semin. Oncol. 2006, 33, 631-641. [CrossRef]

14. Oakley, R.H.; Cidlowski, J.A. The Biology of the Glucocorticoid Receptor: New Signaling Mechanisms in Health and Disease. J. Allergy Clin. Immunol. 2013, 132, 1033-1044. [CrossRef] [PubMed]

15. Pascual-Le Tallec, L.; Lombès, M. The Mineralocorticoid Receptor: A Journey Exploring Its Diversity and Specificity of Action. Mol. Endocrinol. 2005, 19, 2211-2221. [CrossRef]

16. Pratt, W.B.; Galigniana, M.D.; Morishima, Y.; Murphy, P.J.M. Role of Molecular Chaperones in Steroid Receptor Action. Essays Biochem. 2004, 40, 41-58. [CrossRef]

17. Picard, D. Chaperoning Steroid Hormone Action. Trends Endocrinol. Metab. 2006, 17, 229-235. [CrossRef]

18. DeMarzo, A.M.; Beck, C.A.; Onate, S.A.; Edwards, D.P. Dimerization of Mammalian Progesterone Receptors Occurs in the Absence of DNA and Is Related to the Release of the 90-KDa Heat Shock Protein. Proc. Natl. Acad. Sci. USA 1991, 88, 72-76. [CrossRef]

19. Grimm, S.L.; Hartig, S.M.; Edwards, D.P. Progesterone Receptor Signaling Mechanisms. J. Mol. Biol. 2016, 428, 3831-3849. [CrossRef]

20. Savory, J.G.A.; Préfontaine, G.G.; Lamprecht, C.; Liao, M.; Walther, R.F.; Lefebvre, Y.A.; Haché, R.J.G. Glucocorticoid Receptor Homodimers and Glucocorticoid-Mineralocorticoid Receptor Heterodimers Form in the Cytoplasm through Alternative Dimerization Interfaces. Mol. Cell Biol. 2001, 21, 781-793. [CrossRef]

21. Tetel, M.J.; Jung, S.; Carbajo, P.; Ladtkow, T.; Skafar, D.F.; Edwards, D.P. Hinge and Amino-Terminal Sequences Contribute to Solution Dimerization of Human Progesterone Receptor. Mol. Endocrinol. 1997, 11, 1114-1128. [CrossRef]

22. Doan, T.B.; Graham, J.D.; Clarke, C.L. Emerging Functional Roles of Nuclear Receptors in Breast Cancer. J. Mol. Endocrinol. 2017, 58, R169-R190. [CrossRef] [PubMed]

23. Daniel, A.R.; Gaviglio, A.L.; Czaplicki, L.M.; Hillard, C.J.; Housa, D.; Lange, C.A. The Progesterone Receptor Hinge Region Regulates the Kinetics of Transcriptional Responses through Acetylation, Phosphorylation, and Nuclear Retention. Mol. Endocrinol. 2010, 24, 2126-2138. [CrossRef]

24. Fuentes, N.; Silveyra, P. Estrogen receptor signaling mechanisms. In Advances in Protein Chemistry and Structural Biology; Elsevier Inc.: Amsterdam, The Netherlands, 2019; Volume 116, pp. 135-170, ISBN 9780128155615.

25. Clarke, R.B.; Anderson, E.; Howell, A. Steroid Receptors in Human Breast Cancer. Trends Endocrinol. Metab. 2004, 15, 316-323. [CrossRef] [PubMed]

26. Hudson, W.H.; Youn, C.; Ortlund, E.A. Crystal Structure of the Mineralocorticoid Receptor DNA Binding Domain in Complex with DNA. PLoS ONE 2014, 9, e107000. [CrossRef]

27. Tang, Q.; Chen, Y.; Meyer, C.; Geistlinger, T.; Lupien, M.; Wang, Q.; Liu, T.; Zhang, Y.; Brown, M.; Liu, X.S. A Comprehensive View of Nuclear Receptor Cancer Cistromes. Cancer Res. 2011, 71, 6940-6947. [CrossRef] [PubMed]

28. Nelson, C.C.; Hendy, S.C.; Shukin, R.J.; Cheng, H.; Bruchovsky, N.; Koop, B.F.; Rennie, P.S. Determinants of DNA Sequence Specificity of the Androgen, Progesterone, and Glucocorticoid Receptors: Evidence for Differential Steroid Receptor Response Elements. Mol. Endocrinol. 1999, 13, 2090-2107. [CrossRef]

29. Beato, M.; Wright, R.H.G.; Dily, F. Le 90 YEARS OF PROGESTERONE: Molecular Mechanisms of Progesterone Receptor Action on the Breast Cancer Genome. J. Mol. Endocrinol. 2020, 65, T65-T79. [CrossRef]

30. Scarpin, K.M.; Graham, J.D.; Mote, P.A.; Clarke, C.L. Progesterone Action in Human Tissues: Regulation by Progesterone Receptor (PR) Isoform Expression, Nuclear Positioning and Coregulator Expression. Nucl. Recept. Signal. 2009, 7, 1-13. [CrossRef]

31. Wójcik, C.; DeMartino, G.N. Intracellular Localization of Proteasomes. Int. J. Biochem. Cell Biol. 2003, 35, 579-589. [CrossRef] 
32. Cicatiello, L.; Addeo, R.; Sasso, A.; Altucci, L.; Petrizzi, V.B.; Borgo, R.; Cancemi, M.; Caporali, S.; Caristi, S.; Scafoglio, C.; et al. Estrogens and Progesterone Promote Persistent CCND1 Gene Activation during G1 by Inducing Transcriptional Derepression via C-Jun/c-Fos/Estrogen Receptor (Progesterone Receptor) Complex Assembly to a Distal Regulatory Element and Recruitment of Cyclin D1 T. Mol. Cell Biol. 2004, 24, 7260-7274. [CrossRef]

33. Stavreva, D.A.; Müller, W.G.; Hager, G.L.; Smith, C.L.; McNally, J.G. Rapid Glucocorticoid Receptor Exchange at a Promoter Is Coupled to Transcription and Regulated by Chaperones and Proteasomes. Mol. Cell Biol. 2004, 24, 2682-2697. [CrossRef] [PubMed]

34. Saladin, K. Anatomy \& Physiology: The Unity of Form and Function, 6th ed.; McGraw-Hill: New York, NY, USA, 2012.

35. Shao, W.; Brown, M. Advances in Estrogen Receptor Biology: Prospects for Improvements in Targeted Breast Cancer Therapy. Breast Cancer Res. 2003, 6, 39. [CrossRef] [PubMed]

36. Lewis, J.S.; Jordan, V.C. Selective Estrogen Receptor Modulators (SERMs): Mechanisms of Anticarcinogenesis and Drug Resistance. Mutat. Res. Mol. Mech. Mutagen. 2005, 591, 247-263. [CrossRef]

37. Hughes, Z.; Liu, F.; Marquis, K.; Muniz, L.; Pangalos, M.; Ring, R.; Whiteside, G.; Brandon, N. Estrogen Receptor Neurobiology and Its Potential for Translation into Broad Spectrum Therapeutics for CNS Disorders. Curr. Mol. Pharm. 2009, 2, 215-236. [CrossRef]

38. Xiao, J.; Wang, N.; Sun, B.; Cai, G. Estrogen Receptor Mediates the Effects of Pseudoprotodiocsin on Adipogenesis in 3T3-L1 Cells. Am. J. Physiol. Physiol. 2010, 299, C128-C138. [CrossRef]

39. Pagano, M.T.; Ortona, E.; Dupuis, M.L. A Role for Estrogen Receptor Alpha36 in Cancer Progression. Front. Endocrinol. 2020, 11, 506. [CrossRef]

40. Zhou, Y.; Liu, X. The Role of Estrogen Receptor Beta in Breast Cancer. Biomark Res. 2020, 8, 39. [CrossRef]

41. Jensen, E.V. On the Mechanism of Estrogen Action. Perspect. Biol. Med. 1962, 6, 47-60. [CrossRef]

42. Park, Y.R.; Lee, J.; Jung, J.H.; Kim, W.W.; Park, C.S.; Lee, R.K.; Chae, Y.S.; Lee, S.J.; Park, J.-Y.; Park, J.Y.; et al. Absence of Estrogen Receptor Is Associated with Worse Oncologic Outcome in Patients Who Were Received Neoadjuvant Chemotherapy for Breast Cancer. Asian J. Surg. 2020, 43, 467-475. [CrossRef] [PubMed]

43. Kumar, M.; Salem, K.; Tevaarwerk, A.J.; Strigel, R.M.; Fowler, A.M. Recent Advances in Imaging Steroid Hormone Receptors in Breast Cancer. J. Nucl. Med. 2020, 61, 172-176. [CrossRef]

44. van Kruchten, M.; Glaudemans, A.W.J.M.; de Vries, E.F.J.; Beets-Tan, R.G.H.; Schröder, C.P.; Dierckx, R.A.; de Vries, E.G.E.; Hospers, G.A.P. PET Imaging of Estrogen Receptors as a Diagnostic Tool for Breast Cancer Patients Presenting with a Clinical Dilemma. J. Nucl. Med. 2012, 53, 182-190. [CrossRef]

45. Belachew, E.B.; Sewasew, D.T. Molecular Mechanisms of Endocrine Resistance in Estrogen-Receptor-Positive Breast Cancer. Front. Endocrinol. 2021, 12, 188. [CrossRef]

46. Kasielska-Trojan, A.; Danilewicz, M.; Strużyna, J.; Bugaj, M.; Antoszewski, B. The Role of Oestrogen and Progesterone Receptors in Gigantomastia. Arch. Med. Sci. 2019, 33, 1-5. [CrossRef]

47. Haque, M.M.; Desai, K.V. Pathways to Endocrine Therapy Resistance in Breast Cancer. Front. Endocrinol. 2019, 10, 573. [CrossRef]

48. Bhattacharjee, A.; Hossain, M.U.; Chowdhury, Z.M.; Rahman, S.M.A.; Bhuyan, Z.A.; Salimullah, M.; Keya, C.A. Insight of Druggable Cannabinoids against Estrogen Receptor $\beta$ in Breast Cancer. J. Biomol. Struct. Dyn. 2021, 39, 1688-1697. [CrossRef] [PubMed]

49. Park, H.; McEachon, J.D.; Pollock, J.A. Synthesis and Characterization of Hydrogen Peroxide Activated Estrogen Receptor Beta Ligands. Bioorg. Med. Chem. 2019, 27, 2075-2082. [CrossRef] [PubMed]

50. Crandall, D.L.; Busler, D.E.; Novak, T.J.; Weber, R.V.; Kral, J.G. Identification of Estrogen Receptor $\beta$ RNA in Human Breast and Abdominal Subcutaneous Adipose Tissue. Biochem. Biophys. Res. Commun. 1998, 248, 523-526. [CrossRef]

51. Kuiper, G.G.J.M.; Shughrue, P.J.; Merchenthaler, I.; Gustafsson, J.-Å. The Estrogen Receptor $\beta$ Subtype: A Novel Mediator of Estrogen Action in Neuroendocrine Systems. Front. Neuroendocr. 1998, 19, 253-286. [CrossRef]

52. Balla, B.; Sárvári, M.; Kósa, J.P.; Kocsis-Deák, B.; Tobiás, B.; Árvai, K.; Takács, I.; Podani, J.; Liposits, Z.; Lakatos, P. Long-Term Selective Estrogen Receptor-Beta Agonist Treatment Modulates Gene Expression in Bone and Bone Marrow of Ovariectomized Rats. J. Steroid Biochem. Mol. Biol. 2019, 188, 185-194. [CrossRef] [PubMed]

53. Liu, J.Y.H.; Lin, G.; Fang, M.; Rudd, J.A. Localization of Estrogen Receptor ER $\alpha$, ER $\beta$ and GPR30 on Myenteric Neurons of the Gastrointestinal Tract and Their Role in Motility. Gen. Comp. Endocrinol. 2019, 272, 63-75. [CrossRef]

54. Tamer, S.A.; Yıldırım, A.; Arabacı, Ş.; Çiftçi, S.; Akın, S.; Sarı, E.; Köroğlu, M.K.; Ercan, F.; Yüksel, M.; Çevik, Ö.; et al. Treatment with Estrogen Receptor Agonist ERß Improves Torsion-Induced Oxidative Testis Injury in Rats. Life Sci. 2019, 222, $203-211$. [CrossRef] [PubMed]

55. Le Moëne, O.; Stavarache, M.; Ogawa, S.; Musatov, S.; Ågmo, A. Estrogen Receptors $\alpha$ and $\beta$ in the Central Amygdala and the Ventromedial Nucleus of the Hypothalamus: Sociosexual Behaviors, Fear and Arousal in Female Rats during Emotionally Challenging Events. Behav. Brain Res. 2019, 367, 128-142. [CrossRef]

56. Kim, H.; Park, J.; Leem, H.; Cho, M.; Yoon, J.-H.; Maeng, H.-J.; Lee, Y. Rhododendrin-Induced RNF146 Expression via Estrogen Receptor $\beta$ Activation Is Cytoprotective Against 6-OHDA-Induced Oxidative Stress. Int. J. Mol. Sci. 2019, 20, 1772. [CrossRef]

57. Han, S.J.; Jung, S.Y.; Wu, S.-P.; Hawkins, S.M.; Park, M.J.; Kyo, S.; Qin, J.; Lydon, J.P.; Tsai, S.Y.; Tsai, M.-J.; et al. Estrogen Receptor $\beta$ Modulates Apoptosis Complexes and the Inflammasome to Drive the Pathogenesis of Endometriosis. Cell 2015, 163, 960-974. [CrossRef] 
58. Ibrahim, A.; Hugerth, L.W.; Hases, L.; Saxena, A.; Seifert, M.; Thomas, Q.; Gustafsson, J.; Engstrand, L.; Williams, C. Colitisinduced Colorectal Cancer and Intestinal Epithelial Estrogen Receptor Beta Impact Gut Microbiota Diversity. Int. J. Cancer 2019, 144, 3086-3098. [CrossRef]

59. Majumdar, S.; Rinaldi, J.C.; Malhotra, N.R.; Xie, L.; Hu, D.-P.; Gauntner, T.D.; Grewal, H.S.; Hu, W.-Y.; Kim, S.H.; Katzenellenbogen, J.A.; et al. Differential Actions of Estrogen Receptor $\alpha$ and $\beta$ via Nongenomic Signaling in Human Prostate Stem and Progenitor Cells. Endocrinology 2019, 160, 2692-2708. [CrossRef] [PubMed]

60. Liang, L.; Williams, M.D.; Bell, D. Expression of PTEN, Androgen Receptor, HER2/Neu, Cytokeratin 5/6, Estrogen Receptor-Beta, HMGA2, and PLAG1 in Salivary Duct Carcinoma. Head Neck Pathol. 2019, 13, 529-534. [CrossRef] [PubMed]

61. Rani, A.; Stebbing, J.; Giamas, G.; Murphy, J. Endocrine Resistance in Hormone Receptor Positive Breast Cancer-From Mechanism to Therapy. Front. Endocrinol. 2019, 10, 245. [CrossRef]

62. Hamilton, K.J.; Hewitt, S.C.; Arao, Y.; Korach, K.S. Estrogen hormone biology. In Nuclear Receptors in Development and Disease; Forrest, D., Tsai, S.B.T.-C.T.D.B., Eds.; Academic Press: Cambridge, MA, USA, 2017; Volume 125, pp. 109-146, ISBN 0070-2153.

63. Omoto, Y.; Iwase, H. Clinical Significance of Estrogen Receptor $\beta$ in Breast and Prostate Cancer from Biological Aspects. Cancer Sci. 2015, 106, 337-343. [CrossRef] [PubMed]

64. Zhao, C.; Dahlman-Wright, K.; Gustafsson, J.-Å. Estrogen Receptor $\beta$ : An Overview and Update. Nucl. Recept. Signal. 2008, 6, nrs.06003. [CrossRef]

65. Castoria, G.; Migliaccio, A.; Giovannelli, P.; Auricchio, F. Cell Proliferation Regulated by Estradiol Receptor: Therapeutic Implications. Steroids 2010, 75, 524-527. [CrossRef] [PubMed]

66. Giraldi, T.; Giovannelli, P.; Di Donato, M.; Castoria, G.; Migliaccio, A.; Auricchio, F. Steroid Signaling Activation and Intracellular Localization of Sex Steroid Receptors. J. Cell Commun. Signal. 2010, 4, 161-172. [CrossRef]

67. Green, K.A.; Carroll, J.S. Oestrogen-Receptor-Mediated Transcription and the Influence of Co-Factors and Chromatin State. Nat. Rev. Cancer 2007, 7, 713-722. [CrossRef]

68. Carroll, J.S.; Liu, X.S.; Brodsky, A.S.; Li, W.; Meyer, C.A.; Szary, A.J.; Eeckhoute, J.; Shao, W.; Hestermann, E.V.; Geistlinger, T.R.; et al. Chromosome-Wide Mapping of Estrogen Receptor Binding Reveals Long-Range Regulation Requiring the Forkhead Protein FoxA1. Cell 2005, 122, 33-43. [CrossRef]

69. Hewitt, S.C.; Li, L.; Grimm, S.A.; Chen, Y.; Liu, L.; Li, Y.; Bushel, P.R.; Fargo, D.; Korach, K.S. Research Resource: Whole-Genome Estrogen Receptor $\alpha$ Binding in Mouse Uterine Tissue Revealed by ChIP-Seq. Mol. Endocrinol. 2012, 26, 887-898. [CrossRef]

70. Carroll, J.S.; Brown, M. Estrogen Receptor Target Gene: An Evolving Concept. Mol. Endocrinol. 2006, 20, 1707-1714. [CrossRef] [PubMed]

71. Maselli, A.; Pierdominici, M.; Vitale, C.; Ortona, E. Membrane Lipid Rafts and Estrogenic Signalling: A Functional Role in the Modulation of Cell Homeostasis. Apoptosis 2015, 20, 671-678. [CrossRef] [PubMed]

72. Smith, C.L. Cross-Talk between Peptide Growth Factor and Estrogen Receptor Signaling Pathways. Biol. Reprod. 1998, 58, 627-632. [CrossRef]

73. Simpson, E. Sources of Estrogen and Their Importance. J. Steroid Biochem. Mol. Biol. 2003, 86, 225-230. [CrossRef]

74. Longcope, C. Endocrine Function of the Postmenopausal Ovary. J. Soc. Gynecol. Investig. 2001, 8, S67-S68. [CrossRef]

75. Kelsey, J.L.; Gammon, M.D.; John, E.M. Reproductive Factors and Breast Cancer. Epidemiol. Rev. 1993, 15, 36-47. [CrossRef] [PubMed]

76. Titus-Ernstoff, L.; Longnecker, M.P.; Newcomb, P.A.; Dain, B.; Greenberg, E.R.; Mittendorf, R.; Stampfer, M.; Willett, W. Menstrual Factors in Relation to Breast Cancer Risk. Cancer Epidemiol. Prev. Biomark. 1998, 7, 783-789.

77. Rees, M. The Age of Menarche. ORGYN 1995, 4, 2-4.

78. Zhao, L.; Huang, S.; Mei, S.; Yang, Z.; Xu, L.; Zhou, N.; Yang, Q.; Shen, Q.; Wang, W.; Le, X.; et al. Pharmacological Activation of Estrogen Receptor Beta Augments Innate Immunity to Suppress Cancer Metastasis. Proc. Natl. Acad. Sci. USA 2018, 115, E3673-E3681. [CrossRef]

79. Hinsche, O.; Girgert, R.; Emons, G.; Gründker, C. Estrogen Receptor $\beta$ Selective Agonists Reduce Invasiveness of Triple-Negative Breast Cancer Cells. Int. J. Oncol. 2015, 46, 878-884. [CrossRef] [PubMed]

80. Song, P.; Li, Y.; Dong, Y.; Liang, Y.; Qu, H.; Qi, D.; Lu, Y.; Jin, X.; Guo, Y.; Jia, Y.; et al. Estrogen Receptor $\beta$ Inhibits Breast Cancer Cells Migration and Invasion through CLDN6-Mediated Autophagy. J. Exp. Clin. Cancer Res. 2019, 38, 354. [CrossRef]

81. Braschi, B.; Denny, P.; Gray, K.; Jones, T.; Seal, R.; Tweedie, S.; Yates, B.; Bruford, E. Genenames.Org: The HGNC and VGNC Resources in 2019. Nucleic Acids Res. 2019, 47, D786-D792. [CrossRef] [PubMed]

82. Singhal, H.; Greene, M.E.; Zarnke, A.L.; Laine, M.; Al Abosy, R.; Chang, Y.F.; Dembo, A.G.; Schoenfelt, K.; Vadhi, R.; Qiu, X.; et al. Progesterone Receptor Isoforms, Agonists and Antagonists Differentially Reprogram Estrogen Signaling. Oncotarget 2018, 9 , 4282-4300. [CrossRef]

83. Ballaré, C.; Castellano, G.; Gaveglia, L.; Althammer, S.; González-Vallinas, J.; Eyras, E.; Le Dily, F.; Zaurin, R.; Soronellas, D.; Vicent, G.P.; et al. Nucleosome-Driven Transcription Factor Binding and Gene Regulation. Mol. Cell 2013, 49, 67-79. [CrossRef] [PubMed]

84. Proietti, C.J.; Cenciarini, M.E.; Elizalde, P.V. Revisiting Progesterone Receptor (PR) Actions in Breast Cancer: Insights into PR Repressive Functions. Steroids 2018, 133, 75-81. [CrossRef] [PubMed]

85. Clarke, C.L.; Graham, J.D. Non-Overlapping Progesterone Receptor Cistromes Contribute to Cell-Specific Transcriptional Outcomes. PLoS ONE 2012, 7, e35859. [CrossRef] 
86. Richer, J.K.; Jacobsen, B.M.; Manning, N.G.; Abel, M.G.; Wolf, D.M.; Horwitz, K.B. Differential Gene Regulation by the Two Progesterone Receptor Isoforms in Human Breast Cancer Cells. J. Biol. Chem. 2002, 277, 5209-5218. [CrossRef]

87. Khan, J.A.; Bellance, C.; Guiochon-Mantel, A.; Lombès, M.; Loosfelt, H. Differential Regulation of Breast Cancer-Associated Genes by Progesterone Receptor Isoforms PRA and PRB in a New Bi-Inducible Breast Cancer Cell Line. PLoS ONE 2012, 7, e45993. [CrossRef]

88. Diep, C.H.; Knutson, T.P.; Lange, C.A. Active FOXO1 Is a Key Determinant of Isoform-Specific Progesterone Receptor Transactivation and Senescence Programming. Mol. Cancer Res. 2016, 14, 141-162. [CrossRef]

89. McFall, T.; McKnight, B.; Rosati, R.; Kim, S.; Huang, Y.; Viola-Villegas, N.; Ratnam, M. Progesterone Receptor a Promotes Invasiveness and Metastasis of Luminal Breast Cancer by Suppressing Regulation of Critical MicroRNAs by Estrogen. J. Biol. Chem. 2018, 293, 1163-1177. [CrossRef]

90. Giangrande, P.H.; Kimbrel, E.A.; Edwards, D.P. The Opposing Transcriptional Activities of the Two Isoforms of the Human Progesterone Receptor Are Due to Differential Cofactor Binding. Mol. Cell. Biol. 2000, 20, 3102-3115. [CrossRef] [PubMed]

91. Bateman, A.; Martin, M.-J.; Orchard, S.; Magrane, M.; Agivetova, R.; Ahmad, S.; Alpi, E.; Bowler-Barnett, E.H.; Britto, R.; Bursteinas, B.; et al. UniProt: The Universal Protein Knowledgebase in 2021. Nucleic Acids Res. 2021, 49, D480-D489. [CrossRef]

92. Piasecka, D.; Składanowski, A.C.; Kordek, R.; Romańska, H.M.; Sądej, R. Aspekty Regulacji Aktywności Receptora Progesteronu (PR)-Znaczenie w Progresji Raka Gruczołu Piersiowego. Postepy Biochem. 2015, 61, 198-206.

93. Cohen-Solal, K.; Bailly, A.; Rauch, C.; Quesne, M.; Milgrom, E. Specific Binding of Progesterone Receptor to Progesteroneresponsive Elements Does Not Require Prior Dimerization. Eur. J. Biochem. 1993, 214, 189-195. [CrossRef] [PubMed]

94. Abdel-Hafiz, H.A.; Horwitz, K.B. Post-Translational Modifications of the Progesterone Receptors. J. Steroid Biochem. Mol. Biol. 2014, 140, 80-89. [CrossRef] [PubMed]

95. Hagan, C.R.; Lange, C.A. Molecular Determinants of Context-Dependent Progesterone Receptor Action in Breast Cancer. Cancer Cell Signal. Target. Signal. Pathw. Towar Ther. Approaches Cancer 2014, 12, 231-252. [CrossRef]

96. Qiu, M.; Lange, C.A. MAP Kinases Couple Multiple Functions of Human Progesterone Receptors: Degradation, Transcriptional Synergy, and Nuclear Association. J. Steroid Biochem. Mol. Biol. 2003, 85, 147-157. [CrossRef]

97. Chung, H.H.; Sze, S.K.; En Woo, A.R.; Sun, Y.; Sim, K.H.; Dong, X.M.; Lin, V.C.L. Lysine Methylation of Progesterone Receptor at Activation Function 1 Regulates Both Ligand-Independent Activity and Ligand Sensitivity of the Receptor. J. Biol. Chem. 2014, 289, 5704-5722. [CrossRef]

98. Analysis of the Forkhead Box A1 (FOXA1)-Dependent and ORG2058 (ORG058)-Regulated Transcriptome in Human MCF-10A AB32 Mammary Epithelial Cells. Available online: https:/ /www.signalingpathways.org/datasets/dataset.jsf?doi=10.1621/n4 $3 \mathrm{gIWhFJ}$ (accessed on 26 August 2021).

99. Analysis of the Progesterone (P4) and R5020-Dependent ESR1, PGR and EP300 Cistromes in T47D and MCF-7 Human Breast Cancer Cells. Available online: https://128.249.193.43/datasets/dataset.jsf?doi=10.1621/9pIjse2rDj (accessed on 26 August 2021).

100. Analysis of the MEK1/2-Regulated Transcriptome in R5020-Treated Human T47D Cells. Available online: https://www signalingpathways.org/datasets / dataset.jsf?doi=10.1621/XGSeVZH1LR (accessed on 26 August 2021).

101. Hilton, H.N.; Graham, J.D.; Clarke, C.L. Minireview: Progesterone Regulation of Proliferation in the Normal Human Breast and in Breast Cancer: A Tale of Two Scenarios? Mol. Endocrinol. 2015, 29, 1230-1242. [CrossRef]

102. Lyytinen, H.; Dyba, T.; Ylikorkala, O.; Pukkala, E. A case-control study on hormone therapy as a risk factor for breast cancer in finland. Maturitas 2009, 63, S50. [CrossRef]

103. Li, C.I.; Beaber, E.F.; Tang, M.T.C.; Porter, P.L.; Daling, J.R.; Malone, K.E. Effect of Depo-Medroxyprogesterone Acetate on Breast Cancer Risk among Women 20 to 44 Years of Age. Cancer Res. 2012, 72, 2028-2035. [CrossRef]

104. Banks, E.; Beral, V.; Bull, D.; Reeves, G.; Austoker, J.; English, R.; Patnick, J.; Peto, R.; Vessey, M.; Wallis, M.; et al. Breast Cancer and Hormone-Replacement Therapy in the Million Women Study. Lancet 2003, 362, 419-427. [CrossRef]

105. Hunter, D.J.; Colditz, G.A.; Hankinson, S.E.; Malspeis, S.; Spiegelman, D.; Chen, W.; Stampfer, M.J.; Willett, W.C. Oral Contraceptive Use and Breast Cancer: A Prospective Study of Young Women. Cancer Epidemiol. Biomark. Prev. 2010, 19, $2496-2502$. [CrossRef]

106. Soini, T.; Hurskainen, R.; Grénman, S.; Mäenpää, J.; Paavonen, J.; Pukkala, E. Cancer Risk in Women Using the LevonorgestrelReleasing Intrauterine System in Finland. Obs. Gynecol. 2014, 124, 292-299. [CrossRef]

107. Chlebowski, R.T.; Kuller, L.H.; Prentice, R.L.; Stefanick, M.L.; Manson, J.E.; Gass, M.; Aragaki, A.K.; Ockene, J.K.; Lane, D.S.; Sarto, G.E.; et al. Breast Cancer after Use of Estrogen plus Progestin in Postmenopausal Women. N. Engl. J. Med. 2009, 360, 573-587. [CrossRef] [PubMed]

108. Faivre, E.J.; Lange, C.A. Progesterone Receptors Upregulate Wnt-1 to Induce Epidermal Growth Factor Receptor Transactivation and c-Src-Dependent Sustained Activation of Erk1/2 Mitogen-Activated Protein Kinase in Breast Cancer Cells. Mol. Cell Biol. 2007, 27, 466-480. [CrossRef]

109. Hu, T.; Li, C. Convergence between Wnt- $\beta$-Catenin and EGFR Signaling in Cancer. Mol. Cancer 2010, 9, 1-7. [CrossRef] [PubMed]

110. Ohtsu, H.; Dempsey, P.J.; Eguchi, S. ADAMs as Mediators of EGF Receptor Transactivation by G Protein-Coupled Receptors. Am. J. Physiol. Cell Physiol. 2006, 291, C1-C10. [CrossRef] [PubMed]

111. Wang, Z. Transactivation of Epidermal Growth Factor Receptor by g Protein-Coupled Receptors: Recent Progress, Challenges and Future Research. Int. J. Mol. Sci. 2016, 17, 95. [CrossRef] 
112. Schlange, T.; Matsuda, Y.; Lienhard, S.; Huber, A.; Hynes, N.E. Autocrine WNT Signaling Contributes to Breast Cancer Cell Proliferation via the Canonical WNT Pathway and EGFR Transactivation. Breast Cancer Res. 2007, 9, 1-15. [CrossRef]

113. Cattaneo, F.; Guerra, G.; Parisi, M.; De Marinis, M.; Tafuri, D.; Cinelli, M.; Ammendola, R. Cell-Surface Receptors Transactivation Mediated by G Protein-Coupled Receptors. Int. J. Mol. Sci. 2014, 15, 19700-19728. [CrossRef] [PubMed]

114. Hagan, C.R.; Knutson, T.P.; Lange, C.A. A Common Docking Domain in Progesterone Receptor-B Links DUSP6 and CK2 Signaling to Proliferative Transcriptional Programs in Breast Cancer Cells. Nucleic Acids Res. 2013, 41, 8926-8942. [CrossRef] [PubMed]

115. Izzo, F.; Mercogliano, F.; Venturutti, L.; Tkach, M.; Inurrigarro, G.; Schillaci, R.; Cerchietti, L.; Elizalde, P.V.; Proietti, C.J. Progesterone Receptor Activation Downregulates GATA3 by Transcriptional Repression and Increased Protein Turnover Promoting Breast Tumor Growth. Breast Cancer Res. 2014, 16, 491. [CrossRef]

116. Truong, T.H.; Lange, C.A. Deciphering Steroid Receptor Crosstalk in Hormone-Driven Cancers. Endocrinology 2018, 159, 3897-3907. [CrossRef] [PubMed]

117. Mohammed, H.; Russell, I.A.; Stark, R.; Rueda, O.M.; Hickey, T.E.; Tarulli, G.A.; Serandour, A.A.A.; Birrell, S.N.; Bruna, A.; Saadi, A.; et al. Progesterone Receptor Modulates ER $\alpha$ Action in Breast Cancer. Nature 2015, 523, 313-317. [CrossRef]

118. Singhal, H.; Greene, M.E.; Tarulli, G.; Zarnke, A.L.; Bourgo, R.J.; Laine, M.; Chang, Y.F.; Ma, S.; Dembo, A.G.; Raj, G.V.; et al. Genomic Agonism and Phenotypic Antagonism between Estrogen and Progesterone Receptors in Breast Cancer. Sci. Adv. 2016, 2, e1501924. [CrossRef] [PubMed]

119. Kraus, W.L.; Weis, K.E.; Katzenellenbogen, B.S. Inhibitory Cross-Talk between Steroid Hormone Receptors: Differential Targeting of Estrogen Receptor in the Repression of Its Transcriptional Activity by Agonist- and Antagonist-Occupied Progestin Receptors. Mol. Cell Biol. 1995, 15, 1847-1857. [CrossRef]

120. Graham, J.D.; Yeates, C.; Balleine, R.L.; Clarke, C.L.; Milliken, J.S.; Bilous, A.M.; Harvey, S.S. Characterization of Progesterone Receptor A and B Expression in Human Breast Cancer. Cancer Res. 1995, 55, 5063-5068.

121. Mote, P.A.; Bartow, S.; Tran, N.; Clarke, C.L. Loss of Co-Ordinate Expression of Progesterone Receptors A and B Is an Early Event in Breast Carcinogenesis. Breast Cancer Res. Treat. 2002, 72, 163-172. [CrossRef]

122. Sartorius, C.A.; Shen, T.; Horwitz, K.B. Progesterone Receptors A and B Differentially Affect the Growth of Estrogen-Dependent Human Breast Tumor Xenografts. Breast Cancer Res. Treat. 2003, 79, 287-299. [CrossRef]

123. Hopp, T.A.; Weiss, H.L.; Hilsenbeck, S.G.; Cui, Y.; Allred, D.C.; Horwitz, K.B.; Fuqua, S.A.W. Breast Cancer Patients with Progesterone Receptor PR-A-Rich Tumors Have Poorer Disease-Free Survival Rates. Clin. Cancer Res. 2004, 10, 2751-2760. [CrossRef]

124. Mote, P.A.; Gompel, A.; Howe, C.; Hilton, H.N.; Sestak, I.; Cuzick, J.; Dowsett, M.; Hugol, D.; Forgez, P.; Byth, K.; et al. Progesterone Receptor A Predominance Is a Discriminator of Benefit from Endocrine Therapy in the ATAC Trial. Breast Cancer Res. Treat. 2015, 151, 309-318. [CrossRef]

125. Rojas, P.A.; May, M.; Sequeira, G.R.; Elia, A.; Alvarez, M.; Martínez, P.; Gonzalez, P.; Hewitt, S.; He, X.; Perou, C.M.; et al. Progesterone Receptor Isoform Ratio: A Breast Cancer Prognostic and Predictive Factor for Antiprogestin Responsiveness. J. Natl. Cancer Inst. 2017, 109. [CrossRef] [PubMed]

126. Wargon, V.; Riggio, M.; Giulianelli, S.; Sequeira, G.R.; Rojas, P.; May, M.; Polo, M.L.; Gorostiaga, M.A.; Jacobsen, B.; Molinolo, A.; et al. Progestin and Antiprogestin Responsiveness in Breast Cancer Is Driven by the PRA/PRB Ratio via AIB1 or SMRT Recruitment to the CCND1 and MYC Promoters. Int. J. Cancer 2015, 136, 2680-2692. [CrossRef] [PubMed]

127. Burger, H.G. Androgen Production in Women. Fertil. Steril. 2002, 77, 3-5. [CrossRef]

128. Van der Steen, T.; Tindall, D.; Huang, H. Posttranslational Modification of the Androgen Receptor in Prostate Cancer. Int. J. Mol. Sci. 2013, 14, 14833-14859. [CrossRef]

129. Ruizeveld De Winter, J.A.; Trapman, J.; Vermey, M.; Mulder, E.; Zegers, N.D.; Van der Kwast, T.H. Androgen Receptor Expression in Human Tissues: An Immunohistochemical Study. J. Histochem. Cytochem. 1991, 39, 927-936. [CrossRef]

130. Kensler, K.H.; Beca, F.; Baker, G.M.; Heng, Y.J.; Beck, A.H.; Schnitt, S.J.; Hazra, A.; Rosner, B.A.; Eliassen, A.H.; Hankinson, S.E.; et al. Androgen Receptor Expression in Normal Breast Tissue and Subsequent Breast Cancer Risk. NPJ Breast Cancer $2018,4,33$. [CrossRef] [PubMed]

131. Fioretti, F.M.; Sita-Lumsden, A.; Bevan, C.L.; Brooke, G.N. Revising the Role of the Androgen Receptor in Breast Cancer. J. Mol. Endocrinol. 2014, 52, R257-R265. [CrossRef]

132. Garay, J.P.; Park, B.H. Androgen Receptor as a Targeted Therapy for Breast Cancer. Am. J. Cancer Res. 2012, 2, 434-445.

133. Hickey, T.E.; Irvine, C.M.; Dvinge, H.; Tarulli, G.A.; Hanson, A.R.; Ryan, N.K.; Pickering, M.A.; Birrell, S.N.; Hu, D.G.; Mackenzie, P.I.; et al. Expression of Androgen Receptor Splice Variants in Clinical Breast Cancers. Oncotarget 2015, 6, 44728-44744. [CrossRef]

134. Thakkar, A.; Wang, B.; Picon-Ruiz, M.; Buchwald, P.; Ince, T.A. Vitamin D and Androgen Receptor-Targeted Therapy for Triple-Negative Breast Cancer. Breast Cancer Res. Treat. 2016, 157, 77-90. [CrossRef]

135. Nelson, K.A. Androgen Receptor CAG Repeats and Prostate Cancer. Am. J. Epidemiol. 2002, 155, 883-890. [CrossRef] [PubMed]

136. Palazzolo, I.; Gliozzi, A.; Rusmini, P.; Sau, D.; Crippa, V.; Simonini, F.; Onesto, E.; Bolzoni, E.; Poletti, A. The Role of the Polyglutamine Tract in Androgen Receptor. J. Steroid Biochem. Mol. Biol. 2008, 108, 245-253. [CrossRef]

137. Lundin, K.B.; Giwercman, A.; Dizeyi, N.; Giwercman, Y.L. Functional in Vitro Characterisation of the Androgen Receptor GGN Polymorphism. Mol. Cell Endocrinol. 2007, 264, 184-187. [CrossRef] [PubMed]

138. Li, J.; Xiao, F.; Zhang, Y.; Lan, A.; Song, Q.; Zhang, R.; Gu, K.; Chen, P.; Li, Z.; Zhang, X.; et al. Shorter GGN Repeats in Androgen Receptor Gene Would Not Increase the Risk of Prostate Cancer. Technol. Cancer Res. Treat. 2017, 16, 159-166. [CrossRef] 
139. Weng, H.; Li, S.; Huang, J.Y.; He, Z.Q.; Meng, X.Y.; Cao, Y.; Fang, C.; Zeng, X.T. Androgen Receptor Gene Polymorphisms and Risk of Prostate Cancer: A Meta-Analysis. Sci. Rep. 2017, 7, 1-15. [CrossRef] [PubMed]

140. Rebbeck, T.R.; Kantoff, P.W.; Krithivas, K.; Neuhausen, S.; Blackwood, M.A.; Godwin, A.K.; Daly, M.B.; Narod, S.A.; Garber, J.E.; Lynch, H.T.; et al. Modification of BRCA1-Associated Breast Cancer Risk by the Polymorphic Androgen-Receptor CAG Repeat. Am. J. Hum. Genet. 1999, 64, 1371-1377. [CrossRef] [PubMed]

141. Spurdle, A.B.; Antoniou, A.C.; Duffy, D.L.; Pandeya, N.; Kelemen, L.; Chen, X.; Peock, S.; Cook, M.R.; Smith, P.L.; Purdie, D.M.; et al. The Androgen Receptor CAG Repeat Polymorphism and Modification of Breast Cancer Risk in BRCA1 and BRCA2 Mutation Carriers. Breast Cancer Res. 2005, 7. [CrossRef]

142. Christopoulos, P.F.; Vlachogiannis, N.I.; Vogkou, C.T.; Koutsilieris, M. The Role of the Androgen Receptor Signaling in Breast Malignancies. Anticancer Res. 2017, 37, 6533-6540. [CrossRef]

143. Ware, K.E.; Garcia-Blanco, M.A.; Armstrong, A.J.; Dehm, S.M. Biologic and Clinical Significance of Androgen Receptor Variants in Castration Resistant Prostate Cancer. Endocr. Relat Cancer 2014, 21, T87-T103. [CrossRef]

144. Hsu, F.N.; Chen, M.C.; Chiang, M.C.; Lin, E.; Lee, Y.T.; Huang, P.H.; Lee, G.S.; Lin, H. Regulation of Androgen Receptor and Prostate Cancer Growth by Cyclin-Dependent Kinase 5. J. Biol. Chem. 2011, 286, 33141-33149. [CrossRef] [PubMed]

145. Yang, C.-S.; Vitto, M.J.; Busby, S.A.; Garcia, B.A.; Kesler, C.T.; Gioeli, D.; Shabanowitz, J.; Hunt, D.F.; Rundell, K.; Brautigan, D.L.; et al. Simian Virus 40 Small $\mathrm{t}$ Antigen Mediates Conformation-Dependent Transfer of Protein Phosphatase 2A onto the Androgen Receptor. Mol. Cell Biol. 2005, 25, 1298-1308. [CrossRef]

146. Lin, H.K.; Yeh, S.; Kang, H.Y.; Chang, C. Akt Suppresses Androgen-Induced Apoptosis by Phosphorylating and Inhibiting Androgen Receptor. Proc. Natl. Acad. Sci. USA 2001, 98, 7200-7205. [CrossRef] [PubMed]

147. Palazzolo, I.; Burnett, B.G.; Young, J.E.; Brenne, P.L.; La Spada, A.R.; Fischbeck, K.H.; Howell, B.W.; Pennuto, M. Akt Blocks Ligand Binding and Protects against Expanded Polyglutamine Androgen Receptor Toxicity. Hum. Mol. Genet. 2007, 16, 1593-1603. [CrossRef] [PubMed]

148. Lin, H.K.; Hu, Y.C.; Yang, L.; Altuwaijri, S.; Chen, Y.T.; Kang, H.Y.; Chang, C. Suppression Versus Induction of Androgen Receptor Functions by the Phosphatidylinositol 3-Kinase/Akt Pathway in Prostate Cancer LNCaP Cells with Different Passage Numbers. J. Biol. Chem. 2003, 278, 50902-50907. [CrossRef]

149. Chen, S.; Gulla, S.; Cai, C.; Balk, S.P. Androgen Receptor Serine 81 Phosphorylation Mediates Chromatin Binding and Transcriptional Activation. J. Biol. Chem. 2012, 287, 8571-8583. [CrossRef]

150. Mahajan, K.; Challa, S.; Coppola, D.; Lawrence, H.; Luo, Y.; Gevariya, H.; Zhu, W.; Chen, Y.A.; Lawrence, N.J.; Mahajan, N.P. Effect of Ack1 Tyrosine Kinase Inhibitor on Ligand-Independent Androgen Receptor Activity. Prostate 2010, 70, 1274-1285. [CrossRef]

151. Mahajan, N.P.; Liu, Y.; Majumder, S.; Warren, M.R.; Parker, C.E.; Mohler, J.L.; Earp, H.S.; Whang, Y.E. Activated Cdc42-Associated Kinase Ack1 Promotes Prostate Cancer Progression via Androgen Receptor Tyrosine Phosphorylation. Proc. Natl. Acad. Sci. USA 2007, 104, 8438-8443. [CrossRef]

152. Mahajan, N.P.; Whang, Y.E.; Mohler, J.L.; Earp, H.S. Activated Tyrosine Kinase Ack1 Promotes Prostate Tumorigenesis: Role of Ack1 in Polyubiquitination of Tumor Suppressor Wwox. Cancer Res. 2005, 65, 10514-10523. [CrossRef]

153. Liu, Y.; Karaca, M.; Zhang, Z.; Gioeli, D.; Earp, H.S.; Whang, Y.E. Dasatinib Inhibits Site-Specific Tyrosine Phosphorylation of Androgen Receptor by Ack1 and Src Kinases. Oncogene 2010, 29, 3208-3216. [CrossRef] [PubMed]

154. Shu, S.K.; Liu, Q.; Coppola, D.; Cheng, J.Q. Phosphorylation and Activation of Androgen Receptor by Aurora-A. J. Biol. Chem. 2010, 285, 33045-33053. [CrossRef] [PubMed]

155. Chymkowitch, P.; Le May, N.; Charneau, P.; Compe, E.; Egly, J.M. The Phosphorylation of the Androgen Receptor by TFIIH Directs the Ubiquitin/Proteasome Process. EMBO J. 2011, 30, 468-479. [CrossRef]

156. Ponguta, L.A.; Gregory, C.W.; French, F.S.; Wilson, E.M. Site-Specific Androgen Receptor Serine Phosphorylation Linked to Epidermal Growth Factor-Dependent Growth of Castration-Recurrent Prostate Cancer. J. Biol. Chem. 2008, 283, $20989-21001$. [CrossRef] [PubMed]

157. Guo, Z.; Dai, B.; Jiang, T.; Xu, K.; Xie, Y.; Kim, O.; Nesheiwat, I.; Kong, X.; Melamed, J.; Handratta, V.D.; et al. Regulation of Androgen Receptor Activity by Tyrosine Phosphorylation. Cancer Cell 2007, 11, 97. [CrossRef]

158. Gioeli, D.; Black, B.E.; Gordon, V.; Spencer, A.; Kesler, C.T.; Eblen, S.T.; Paschal, B.M.; Weber, M.J. Stress Kinase Signaling Regulates Androgen Receptor Phosphorylation, Transcription, and Localization. Mol. Endocrinol. 2006, 20, 503-515. [CrossRef] [PubMed]

159. Zhou, Z.X.; Kemppainen, J.A.; Wilson, E.M. Identification of Three Proline-Directed Phosphorylation Sites in the Human Androgen Receptor. Mol. Endocrinol. 1995, 9, 605-615. [CrossRef]

160. Gordon, V.; Bhadel, S.; Wunderlich, W.; Zhang, J.A.; Ficarro, S.B.; Mollah, S.A.; Shabanowitz, J.; Hunt, D.F.; Xenarios, I.; Hahn, W.C.; et al. CDK9 Regulates AR Promoter Selectivity and Cell Growth through Serine 81 Phosphorylation. Mol. Endocrinol. 2010, 24, 2267-2280. [CrossRef]

161. Linn, D.E.; Yang, X.; Xie, Y.; Alfano, A.; Deshmukh, D.; Wang, X.; Shimelis, H.; Chen, H.; Li, W.; Xu, K.; et al. Differential Regulation of Androgen Receptor by P1M-1 Kinases via Phosphorylation-Dependent Recruitment of Distinct Ubiquitin E3 Ligases. J. Biol. Chem. 2012, 287, 22959-22968. [CrossRef]

162. Heemers, H.V.; Tindall, D.J. Androgen Receptor (AR) Coregulators: A Diversity of Functions Converging on and Regulating the AR Transcriptional Complex. Endocr. Rev. 2007, 28, 778-808. [CrossRef] 
163. Heinlein, C.A.; Chang, C. Androgen Receptor (AR) Coregulators: An Overview. Endocr. Rev. 2002, 23, 175-200. [CrossRef] [PubMed]

164. Crown, J.; Fabre, A.; Watson, W.; Gallagher, W.; Prencipe, M. PO-446 Targeting Co-Regulators of Hormone-Receptors as a Novel Therapeutic Approach for Prostate and Breast Cancer. ESMO Open 2018, 3, A406-A407. [CrossRef]

165. Niemeier, L.A.; Dabbs, D.J.; Beriwal, S.; Striebel, J.M.; Bhargava, R. Androgen Receptor in Breast Cancer: Expression in Estrogen Receptor-Positive Tumors and in Estrogen Receptor-Negative Tumors with Apocrine Differentiation. Mod. Pathol. 2010, 23, 205-212. [CrossRef] [PubMed]

166. Kensler, K.H.; Poole, E.M.; Heng, Y.J.; Collins, L.C.; Glass, B.; Beck, A.H.; Hazra, A.; Rosner, B.A.; Eliassen, A.H.; Hankinson, S.E.; et al. Androgen Receptor Expression and Breast Cancer Survival: Results from the Nurses' Health Studies. J. Natl. Cancer Inst. 2019, 111, 700-708. [CrossRef]

167. Peters, A.A.; Buchanan, G.; Ricciardelli, C.; Bianco-Miotto, T.; Centenera, M.M.; Harris, J.M.; Jindal, S.; Segara, D.; Jia, L.; Moore, N.L.; et al. Androgen Receptor Inhibits Estrogen Receptor- $\alpha$ Activity and Is Prognostic in Breast Cancer. Cancer Res. 2009, 69, 6131-6140. [CrossRef]

168. Chia, K.M.; Liu, J.; Francis, G.D.; Naderi, A. A Feedback Loop between Androgen Receptor and Erk Signaling in Estrogen Receptor-Negative Breast Cancer. Neoplasia 2011, 13, 154-166. [CrossRef]

169. Mukherjee, A.; Narayan, K.P.; Pal, K.; Kumar, J.M.; Rangaraj, N.; Kalivendi, S.V.; Banerjee, R. Selective Cancer Targeting via Aberrant Behavior of Cancer Cell-Associated Glucocorticoid Receptor. Mol. Ther. 2009, 17, 623-631. [CrossRef]

170. Stechschulte, L.A.; Wuescher, L.; Marino, J.S.; Hill, J.W.; Eng, C.; Hinds, T.D. Glucocorticoid Receptor $\beta$ Stimulates Akt1 Growth Pathway by Attenuation of Pten. J. Biol. Chem. 2014, 289, 17885-17894. [CrossRef] [PubMed]

171. Vandevyver, S.; Dejager, L.; Libert, C. Comprehensive Overview of the Structure and Regulation of the Glucocorticoid Receptor. Endocr. Rev. 2014, 35, 671-693. [CrossRef] [PubMed]

172. Præstholm, S.M.; Correia, C.M.; Grøntved, L. Multifaceted Control of GR Signaling and Its Impact on Hepatic Transcriptional Networks and Metabolism. Front. Endocrinol. 2020, 11. [CrossRef]

173. Wang, Q.; Blackford, J.A.; Song, L.N.; Huang, Y.; Cho, S.; Simons, S.S. Equilibrium Interactions of Corepressors and Coactivators with Agonist and Antagonist Complexes of Glucocorticoid Receptors. Mol. Endocrinol. 2004, 18, 1376-1395. [CrossRef]

174. Weikum, E.R.; Knuesel, M.T.; Ortlund, E.A.; Yamamoto, K.R. Glucocorticoid Receptor Control of Transcription: Precision and Plasticity via Allostery. Nat. Rev. Mol. Cell Biol. 2017, 18, 159-174. [CrossRef] [PubMed]

175. Jääskeläinen, A.; Jukkola, A.; Haapasaari, K.M.; Auvinen, P.; Soini, Y.; Karihtala, P. Cytoplasmic Mineralocorticoid Receptor Expression Predicts Dismal Local Relapse-Free Survival in Non-Triple-Negative Breast Cancer. Anticancer Res. 2019, 39, 5879-5890. [CrossRef]

176. Skor, M.N.; Wonder, E.L.; Kocherginsky, M.; Goyal, A.; Hall, B.A.; Cai, Y.; Conzen, S.D. Glucocorticoid Receptor Antagonism as a Novel Therapy for Triple-Negative Breast Cancer. Clin. Cancer Res. 2013, 19, 6163-6172. [CrossRef]

177. Kino, T.; Manoli, I.; Kelkar, S.; Wang, Y.; Su, Y.A.; Chrousos, G.P. Glucocorticoid Receptor (GR) $\beta$ Has Intrinsic, GR $\alpha$-Independent Transcriptional Activity. Biochem. Biophys. Res. Commun. 2009, 381, 671-675. [CrossRef] [PubMed]

178. Casey, T.M.; Plaut, K. The Role of Glucocorticoids in Secretory Activation and Milk Secretion, a Historical Perspective. J. Mammary Gland Biol. Neoplasia 2007, 12, 293-304. [CrossRef]

179. Peng, Y.; Li, C.X.; Chen, F.; Wang, Z.; Ligr, M.; Melamed, J.; Wei, J.; Gerald, W.; Pagano, M.; Garabedian, M.J.; et al. Stimulation of Prostate Cancer Cellular Proliferation and Invasion by the Androgen Receptor Co-Activator ARA70ß. Am. J. Pathol. 2008, 172, 225-235. [CrossRef]

180. Conde, I.; Paniagua, R.; Fraile, B.; Lucio, J.; Arenas, M.I. Glucocorticoid Receptor Changes Its Cellular Location with Breast Cancer Development. Histol. Histopathol. 2008, 23, 77-85. [CrossRef] [PubMed]

181. West, D.C.; Pan, D.; Tonsing-Carter, E.Y.; Hernandez, K.M.; Pierce, C.F.; Styke, S.C.; Bowie, K.R.; Garcia, T.I.; Kocherginsky, M.; Conzen, S.D. GR and ER Coactivation Alters the Expression of Differentiation Genes and Associates with Improved ER+ Breast Cancer Outcome. Mol. Cancer Res. 2016, 14, 707-719. [CrossRef]

182. Leo, J.C.L.; Guo, C.; Woon, C.T.; Aw, S.E.; Lin, V.C.L. Glucocorticoid and Mineralocorticoid Cross-Talk with Progesterone Receptor to Induce Focal Adhesion and Growth Inhibition in Breast Cancer Cells. Endocrinology 2004, 145, 1314-1321. [CrossRef] [PubMed]

183. Abduljabbar, R.; Negm, O.H.; Lai, C.F.; Jerjees, D.A.; Al-Kaabi, M.; Hamed, M.R.; Tighe, P.J.; Buluwela, L.; Mukherjee, A.; Green, A.R.; et al. Clinical and Biological Significance of Glucocorticoid Receptor (GR) Expression in Breast Cancer. Breast Cancer Res. Treat. 2015, 150, 335-346. [CrossRef] [PubMed]

184. Ritter, H.D.; Antonova, L.; Mueller, C.R. The Unliganded Glucocorticoid Receptor Positively Regulates the Tumor Suppressor Gene BRCA1 through GABP Beta. Mol. Cancer Res. 2012, 10, 558-569. [CrossRef]

185. Pippal, J.B.; Yao, Y.; Rogerson, F.M.; Fuller, P.J. Structural and Functional Characterization of the Interdomain Interaction in the Mineralocorticoid Receptor. Mol. Endocrinol. 2009, 23, 1360-1370. [CrossRef]

186. Fuller, P.J.; Yang, J.; Young, M.J. 30 YEARS OF THE MINERALOCORTICOID RECEPTOR: Coregulators as Mediators of Mineralocorticoid Receptor Signalling Diversity. J. Endocrinol. 2017, 234, T23-T34. [CrossRef]

187. Viengchareun, S.; Le Menuet, D.; Martinerie, L.; Munier, M.; Tallec, L.P.-L.; Lombès, M. The Mineralocorticoid Receptor: Insights into Its Molecular and (Patho)Physiological Biology. Nucl. Recept Signal. 2007, 5, nrs.05012. [CrossRef] 
188. Hultman, M.L.; Krasnoperova, N.V.; Li, S.; Du, S.; Xia, C.; Dietz, J.D.; Lala, D.S.; Welsch, D.J.; Hu, X. The Ligand-Dependent Interaction of Mineralocorticoid Receptor with Coactivator and Corepressor Peptides Suggests Multiple Activation Mechanisms. Mol. Endocrinol. 2005, 19, 1460-1473. [CrossRef]

189. Yang, J.; Fuller, P.J.; Morgan, J.; Shibata, H.; McDonnell, D.P.; Clyne, C.D.; Young, M.J. Use of Phage Display to Identify Novel Mineralocorticoid Receptor-Interacting Proteins. Mol. Endocrinol. 2014, 28, 1571-1584. [CrossRef]

190. Pratt, W.B.; Toft, D.O. Steroid Receptor Interactions with Heat Shock Protein and Immunophilin Chaperones. Endocr. Rev. 1997, 18, 306-360. [CrossRef]

191. Pascual-Le Tallec, L.; Demange, C.; Lombès, M. Human Mineralocorticoid Receptor A and B Protein Forms Produced by Alternative Translation Sites Display Different Transcriptional Activities. Eur. J. Endocrinol. 2004, 150, 585-590. [CrossRef] [PubMed]

192. Nie, H.; Li, J.; Yang, X.M.; Cao, Q.Z.; Feng, M.X.; Xue, F.; Wei, L.; Qin, W.; Gu, J.; Xia, Q.; et al. Mineralocorticoid Receptor Suppresses Cancer Progression and the Warburg Effect by Modulating the MiR-338-3p-PKLR Axis in Hepatocellular Carcinoma. Hepatology 2015, 62, 1145-1159. [CrossRef] [PubMed]

193. Rigiracciolo, D.C.; Scarpelli, A.; Lappano, R.; Pisano, A.; Santolla, M.F.; Avino, S.; de Marco, P.; Bussolati, B.; Maggiolini, M.; de Francesco, E.M. GPER Is Involved in the Stimulatory Effects of Aldosterone in Breast Cancer Cells and Breast Tumor-Derived Endothelial Cells. Oncotarget 2015, 7, 94-111. [CrossRef] [PubMed]

194. Wickert, L.; Watzka, M.; Bolkenius, U.; Bidlingmaier, F.; Ludwig, M. Mineralocorticoid Receptor Splice Variants in Different Human Tissues. Eur. J. Endocrinol. 1998, 138, 702-704. [CrossRef]

195. Szyniarowski, P.; Corcelle-Termeau, E.; Farkas, T.; Hyøer-Hansen, M.; Nylandsted, J.; Kallunki, T.; Jäättelä, M. A Comprehensive SiRNA Screen for Kinases That Suppress Macroautophagy in Optimal Growth Conditions. Autophagy 2011, 7, 892-903. [CrossRef]

196. Martin, P.M.; Rolland, P.H.; Raynaud, J.P. Macromolecular Binding of Dexamethasone as Evidence for the Presence of Mineralocorticoid Receptor in Human Breast Cancer. Cancer Res. 1981, 41, 1222-1226.

197. Ni, H.; Rui, Q.; Zhu, X.; Yu, Z.; Gao, R.; Liu, H. Antihypertensive Drug Use and Breast Cancer Risk: A Metaanalysis of Observational Studies. Oncotarget 2017, 8, 62545-62560. [CrossRef] [PubMed]

198. Kikuchi, R.; Shah, N.P.; Dent, S.F. Strategies to Prevent Cardiovascular Toxicity in Breast Cancer: Is It Ready for Primetime? J. Clin. Med. 2020, 9, 896. [CrossRef]

199. Sharma, P.; Banerjee, R.; Narayan, K.P. Mineralocorticoid Receptor Mediated Liposomal Delivery System for Targeted Induction of Apoptosis in Cancer Cells. Biochim. Biophys. Acta Biomembr. 2016, 1858, 415-421. [CrossRef]

200. Welsh, J. Function of the Vitamin D Endocrine System in Mammary Gland and Breast Cancer. Mol. Cell Endocrinol. 2017, 453, 88-95. [CrossRef]

201. Marik, R.; Fackler, M.J.; Gabrielson, E.; Zeiger, M.A.; Sukumar, S.; Stearns, V.; Umbricht, C.B. DNA Methylation-Related Vitamin D Receptor Insensitivity in Breast Cancer. Cancer Biol. Ther. 2010, 10, 44-53. [CrossRef]

202. Qi, X.; Pramanik, R.; Wang, J.; Schultz, R.M.; Maitra, R.K.; Han, J.; Deluca, H.F.; Chen, G. The P38 and JNK Pathways Cooperate to Trans-Activate Vitamin D Receptor via c-Jun/AP-1 and Sensitize Human Breast Cancer Cells to Vitamin D3-Induced Growth Inhibition. J. Biol. Chem. 2002, 277, 25884-25892. [CrossRef]

203. Ditsch, N.; Toth, B.; Mayr, D.; Lenhard, M.; Gallwas, J.; Weissenbacher, T.; Dannecker, C.; Friese, K.; Jeschke, U. The Association between Vitamin D Receptor Expression and Prolonged Overall Survival in Breast Cancer. J. Histochem. Cytochem. 2012, 60, 121-129. [CrossRef]

204. Tavera-Mendoza, L.E.; Westerling, T.; Libby, E.; Marusyk, A.; Cato, L.; Cassani, R.; Cameron, L.A.; Ficarro, S.B.; Marto, J.A.; Klawitter, J.; et al. Vitamin D Receptor Regulates Autophagy in the Normal Mammary Gland and in Luminal Breast Cancer Cells. Proc. Natl. Acad. Sci. USA 2017, 114, E2186-E2194. [CrossRef] [PubMed]

205. Pike, J.W.; Meyer, M.B.; Lee, S.-M.; Onal, M.; Benkusky, N.A. The Vitamin D Receptor: Contemporary Genomic Approaches Reveal New Basic and Translational Insights. J. Clin. Investig. 2017, 127, 1146-1154. [CrossRef] [PubMed]

206. Iqbal, M.U.N.; Khan, T.A. Association between Vitamin D Receptor (Cdx2, Fok1, Bsm1, Apa1, Bgl1, Taq1, and Poly (A)) Gene Polymorphism and Breast Cancer: A Systematic Review and Meta-Analysis. Tumor Biol. 2017, 39, 101042831773128. [CrossRef] [PubMed]

207. Murray, A.; Madden, S.F.; Synnott, N.C.; Klinger, R.; O'Connor, D.; O’Donovan, N.; Gallagher, W.; Crown, J.; Duffy, M.J. Vitamin D Receptor as a Target for Breast Cancer Therapy. Endocr. Relat. Cancer 2017, 24, 181-195. [CrossRef] [PubMed]

208. Holm, J.; Eriksson, L.; Ploner, A.; Eriksson, M.; Rantalainen, M.; Li, J.; Hall, P.; Czene, K. Assessment of Breast Cancer Risk Factors Reveals Subtype Heterogeneity. Cancer Res. 2017, 77, 3708-3717. [CrossRef]

209. Gaugris, S.; Heaney, R.P.; Boonen, S.; Kurth, H.; Bentkover, J.D.; Sen, S.S. Vitamin D Inadequacy among Post-Menopausal Women: A Systematic Review. QJM Mon. J. Assoc. Physicians 2005, 98, 667-676. [CrossRef]

210. Walsh, J.S.; Bowles, S.; Evans, A.L. Vitamin D in Obesity. Curr. Opin. Endocrinol. Diabetes Obes. 2017, 24, 389-394. [CrossRef]

211. Zhu, H.; Bhagatwala, J.; Huang, Y.; Pollock, N.K.; Parikh, S.; Raed, A.; Gutin, B.; Harshfield, G.A.; Dong, Y. Race/Ethnicity-Specific Association of Vitamin D and Global DNA Methylation: Cross-Sectional and Interventional Findings. PLoS ONE 2016, 11, e0152849. [CrossRef]

212. Dibaba, D.T.; Braithwaite, D.; Akinyemiju, T. Metabolic Syndrome and the Risk of Breast Cancer and Subtypes by Race, Menopause and BMI. Cancers 2018, 10, 299. [CrossRef] [PubMed]

213. Leppert, W.; Strag-Lemanowicz, A. Rola Leczenia Hormonalnego u Pacjentów z Zaawansowaną Chorobą Nowotworową. Med. Paliatywna W. Prakt. 2015, 9, 30-38. 